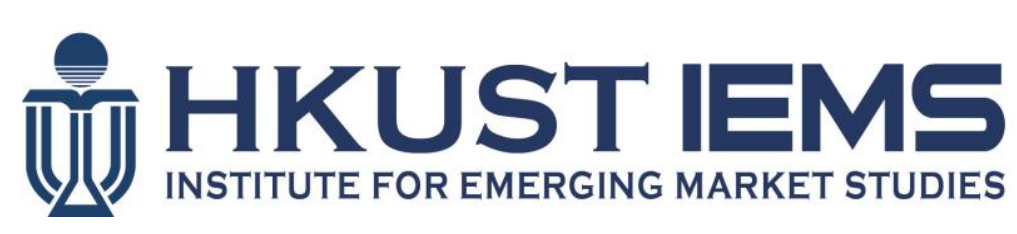

\title{
Permanent Income and Subjective Well-Being
}

\author{
Shu CAI, Albert PARK
}

HKUST IEMS Working Paper No. 2015-08

February 2015

\begin{abstract}
HKUST IEMS working papers are distributed for discussion and comment purposes. The views expressed in these papers are those of the authors and do not necessarily represent the views of HKUST IEMS.
\end{abstract}

More HKUST IEMS working papers are available at: http://iems.ust.hk/WP 


\title{
Permanent Income and Subjective Well-Being
}

\author{
Shu CAl, Albert PARK
}

HKUST IEMS Working Paper No. 2015-08

February 2015

\begin{abstract}
We provide a new explanation for the stronger relationship between income and subjective wellbeing (SWB) found in cross-sectional versus panel studies based on the predictions of a rational expectations model of utility maximization with permanent and transitory income shocks. The model predicts that SWB is affected by unanticipated rather than anticipated income, and is more influenced by permanent rather than transitory income shocks. We hypothesize that share of cross-sectional income variation accounted for by permanent income is greater than the share of changes in income over time accounted for by unanticipated shocks to permanent income. We test our predictions using a unique panel dataset from rural China which includes subjective expectations of future income and actual income in each wave, enabling us to separately identify the effects of unanticipated permanent and transitory income shocks. The results confirm the predictions, providing support for the importance of permanent income in explaining SWB.
\end{abstract}

\section{Author's contact information}

Shu Cai

Department of Economics

The Hong Kong University of Science and Technology

E: scaiaa@ust.hk

Albert Park

HKUST Institute for Emerging Market Studies, Division of Social Science, and Department of Economics

The Hong Kong University of Science and Technology

T : +852 23585981

E: albertpark@ust.hk 


\title{
Permanent Income and Subjective Well-Being ${ }^{1}$
}

\author{
Shu Cai, HKUST \\ Albert Park, HKUST, IZA, and CEPR
}

December 2014

\begin{abstract}
We provide a new explanation for the stronger relationship between income and subjective wellbeing (SWB) found in cross-sectional versus panel studies based on the predictions of a rational expectations model of utility maximization with permanent and transitory income shocks. The model predicts that SWB is affected by unanticipated rather than anticipated income shocks, and is more influenced by changes in permanent rather than transitory income. We hypothesize that share of cross-sectional income variation accounted for by permanent income is greater than the share of changes in household income over time accounted for by unanticipated shocks to permanent income. We test our predictions using a unique panel dataset from rural China which includes subjective expectations of future income, as well as actual income in each wave, enabling us to separately identify the effects of unanticipated permanent and transitory income shocks. The results confirm the predictions, providing empirical support for the importance of permanent income in explaining SWB.
\end{abstract}

Key words: subjective well-being, permanent income, transitory income

JEL Codes: O12, 131

\footnotetext{
${ }^{1}$ We thank Ying Bai, Paul Glewwe, Li Han, Andrew Oswald, and Sujata Visaria for helpful comments, as well as participants at the $9^{\text {th }}$ International Conference on the Chinese Economy at IDREC, France, the $2^{\text {nd }}$ International Wellbeing and Public Policy Conference at Hamilton College, US, and a seminar at the National School of Development, Peking University.
} 


\section{Introduction}

Will more money bring happiness? This question has received a great deal of attention from economists in recent years, but a definitive answer remains elusive. Studies that analyze individual cross-sectional data consistently find that life satisfaction or happiness significantly increases with income, even after controlling for other factors (Blanchflower and Oswald, 2004; Shields and Price, 2005; Graham and Pettinato, 2004; Lelkers, 2006; Carroll et al., 2009; Clark et al., 2005; Di Tella et al., 2003; Frey and Stutzer, 2002). However, evidence from individual-level panel data suggests a much weaker relationship both in magnitude and significance (Winkelmann et al., 1998; Ferrer-i-Carbonell and Frijters, 2004; Luttmer, 2005; Layard et al., 2008).

Theoretical explanations for this difference have mainly been psychological. According to the relative income hypothesis $(\mathrm{RIH})$, people care about relative rather than absolute income, so that SWB increases with own income and decreases with the average income of one's reference group (Duesenberry, 1949; Pollak, 1976; Easterlin 1973, 1974, 1995; Clark et al., 2008). At a given point in time, average income is fixed so individual subjective wellbeing (SWB) increases sharply with own income. However, over time the positive effect of increases in own income may be offset by the negative effect of increasing average incomes. Easterlin (1995) assembled evidence suggesting there is no strong link between the level of GDP and aggregate happiness within countries over time or across countries at a point in time. However, recent studies using more data have found stronger links between happiness and income across countries and within countries over time, reinvigorating the debate over the importance of absolute versus relative income (Stevenson and Wolfers, 2008; Veenhoven and Vergunst, 2013). ${ }^{2}$

\footnotetext{
${ }^{2}$ Another psychological explanation for the lack of increases in happiness with economic growth is that people's assessment of life satisfaction depends on the discrepancy between their aspirations (which rise with income)
} 
This paper provides a new explanation for the seemingly contradictory relationships between income and SWB found in individual cross-sectional and panel analysis, and provides empirical evidence to support it. Our main argument is that an individual's SWB measured at any point in time is most influenced by his or her permanent income, and previous empirical studies do not adequately take into account how different components of income, in particular expected versus unexpected income shocks and permanent versus transitory income, may affect SWB differently. Doing so can reconcile the seemingly contradictory findings of cross-sectional and panel studies using microdata.

If we view measures of SWB as measuring current utility or current plus discounted future expected utility, our hypothesis simply accounts for the fact that money plays purely an instrumental role, affecting utility only by enabling greater consumption of goods and services (Veenhoven, 1991). From this perspective, only differences or changes in income that strongly affect consumption are likely to influence SWB. In the simple dynamic model assuming quadratic utility presented below, consumption in any period is exactly equal to future expected consumption and annualized permanent income, which highlights the notion that only the permanent component of income matters for well-being. Treating SWB implicitly as a measure of utility from consumption enables us to directly apply (we believe for the first time) insights from a large theoretical and empirical literature on the permanent income hypothesis (PIH) to explain and test how income affects SWB.

In permanent income models of consumption, people smooth their consumption (and utility) over time by saving extra income during good years and drawing down savings or borrowing during bad years. The optimal level of consumption in each period thus depends

and their actual income (Easterlin, 2001; Stutzer, 2004). However, the aspiration-adaptation hypothesis (AAH) can only explain the more positive relationship found in cross-sectional comparisons by making strong assumptions that may be unrealistic, for example that at a fixed point in time aspirations are fairly similar among income groups (Easterlin, 2001) or the relative gap between income aspirations and actual income is smaller for rich people (Stutzer, 2004). Empirical tests of the AAH are inconclusive (Di Tella et al., 2010; Gardner and Oswald, 2007). 
on the level of permanent income (Friedman, 1957). In addition, for people with rational expectations, only unexpected income shocks should affect consumption choices. Finally, adjustments of consumption are much greater for permanent income shocks than for transitory income shocks. When shocks have persistent effects on future income flows, such as an accident creating permanent disability, people immediately adjust their level of consumption proportionally (Meyer and Mok, 2013). If an income shock lasts only one period, e.g., winning a lottery, people will save most of the income rather than consume it immediately. Many empirical studies have found behavior consistent with these predictions of the permanent income hypothesis. ${ }^{3},{ }^{4}$

The above insights can explain the inconsistent findings in the literature on the relationship between income and SWB in cross-sectional and panel analysis. In crosssectional comparisons, a large share of income differences reflect differences in lifetime (or permanent) income, with differences associated with transitory shocks being relatively less important. However, when empirically examining the impact of changes in an individual's income over time using panel data, only unexpected permanent income shocks are expected to have a large effect on consumption and well-being, which account for a relatively small share of income changes compared to anticipated income changes and unanticipated transitory income shocks. For this reason it is natural to expect a smaller effect of income on SWB in panel analysis than in cross-sectional analysis. This explanation is distinct from the

\footnotetext{
${ }^{3}$ These studies do not examine the relationship between income and happiness or life satisfaction using individual panel data.

${ }^{4}$ Studies of the effect of anticipated income changes such as expenditure changes from extra wage payments or paying college tuition on consumption confirm consumption smoothing behavior (Browning and Collado, 2001; Souleles, 2000). Studies examining the response of consumption to unanticipated income shocks also generally support the permanent income hypothesis. For example, Hall and Mishkin (1982) found temporary income tax policies have a smaller effect on consumption than more permanent income changes in the US, Paxson (1992) found a higher marginal propensities to save out of transitory income due to rainfall shocks than permanent income among rural households in Thailand, and Pistaferri (2001) found greater savings of transitory income than permanent income shocks in Italy. Earlier studies finding excess sensitivity of consumption to income (Hall, 1978; Flavin, 1981) did not use a robust methodology for predicting anticipated income (Jappelli and Pistaferri, 2010).
} 
argument that variation in panel data has a smaller signal to noise ratio than in cross-sectional data (discussed further below).

To provide empirical support for our explanation, we conduct for the first time an empirical analysis of the impact on SWB of anticipated versus unanticipated and permanent versus transitory income shocks using panel household survey data from China. The lack of previous studies may reflect limitations of most datasets, either due to lack of systematic measurements of SWB or an inability to distinguish clearly between different types of income shocks. Thus, this study extends further the rapidly expanding use of SWB measurements in economic studies (Di Tella and MacCulloch, 2006).

To separately identify different types of income shocks, we combine information on income realizations and subjective expectations of income (Hayashi, 1985; Pistaferri, 2001; Kaufmann and Pistaferri, 2009). Meghir and Pistaferri (2011) explain the advantages of this approach in comparison to those that rely on natural experiments or year-to-year unexplained volatility in income. First, the method does not require the estimation of an income process, and permanent and transitory income shocks can be identified even with short panels. Second, as the expectation of future income is revealed by respondents themselves, there is no problem of "superior information" of respondents compared to the econometrician (Flavin, 1993). Lastly, the approach encompasses all possible types of income shocks rather than relying on a single wealth or income shock based on a quasi-experiment.

The rest of the paper is organized as follows. In Section 2, we present a theoretical model to derive predictions to be taken to the data. Section 3 discusses the empirical strategy for separately identifying the impacts of permanent and transitory income shocks. Section 4 describes the data source and variable construction. Section 5 presents the empirical results. Section 6 presents results for extensions of the benchmark model. Section 7 provides 
evidence on reconciling conflicting estimates from cross-sectional and panel studies, and a final section concludes.

\section{Theoretical Model}

Consider the following utility maximization problem to determine optimal consumption:

$$
\operatorname{Max}_{\left\{c_{t+s}\right\}_{s=0}^{\infty}} U_{t}=E_{t}\left[\sum_{s=0}^{\infty} \beta^{s} u\left(c_{t+s}\right)\right]
$$

subject to intertemporal budget constraint:

$$
w_{t+s+1}=(1+r) w_{t+s}+x_{t+s}-c_{t+s}, \forall \mathrm{s} \geq 0 \text {. }
$$

Here, $w$ is wealth, $x$ is income, $c$ is consumption, and $\beta$ is the discount factor. We assume that $w_{t}$ and $x_{t+s}(\forall \mathrm{s} \geq 0)$ are exogenously given. Without loss of generality, we assume the limit of $(1+r)^{-t} w_{t}$ to be zero as t tends to infinity to rule out any Ponzi games, and that individuals can trade assets freely at the fixed real interest rate $r .{ }^{5}$ The solution is the familiar Euler equation:

$$
u^{\prime}\left(c_{t}\right)=\beta(1+r) E_{t}\left[u^{\prime}\left(c_{t+1}\right)\right]
$$

By assuming quadratic preferences $\left(u(c)=c-(b / 2) c^{2}\right)$ and that the rate of time preference is equal to one plus the interest rate $(\beta(1+r)=1)$, we get a simple expression for optimal consumption (Hall, 1978):

$$
E_{t} c_{t+1}=c_{t}
$$

In words, the forecast of optimal consumption in the next period equals current consumption, so that current consumption captures both current utility and expected future utility. Equation (1) implies that a change in consumption from $t$ to $t+1$ cannot be predicted on the basis of information available at $t$. Applying (1) forward through time, we have $E_{t} c_{t+s}=c_{t}$ for all $\mathrm{s}>1$.

\footnotetext{
${ }^{5}$ We consider the cases of a finite time horizon and liquidity constraints in subsequent analysis.
} 
Using $E_{t} c_{t+s}=c_{t}$ and aggregating the intertemporal budget constraints, we can derive the following expression for consumption:

$$
c_{t}=r\left[w_{t}+\sum_{s=0}^{\infty}\left(\frac{1}{1+r}\right)^{s+1} E_{t} x_{t+s}\right] \equiv y_{t}^{P}
$$

$y_{t}^{P}$ is defined as the annual value of total resources, consisting of current wealth, $w_{t}$, and current and future income flows $\left\{x_{t+s}\right\}, s=0,1,2, \cdots, \infty$. We call $y_{t}^{P}$ the permanent income at time $t$. Equation (2) implies that consumption changes one-to-one with changes in permanent income.

Furthermore, by substituting the intertemporal budget constraint at time $t$ into (2), and reorganizing terms, we can derive the following:

$$
c_{t+1}-c_{t}=r \sum_{s=0}^{\infty}\left(\frac{1}{1+r}\right)^{s+1}\left(E_{t+1}-E_{t}\right) x_{t+s+1}
$$

Equation (3) indicates that only unexpected innovations of future income arriving at time $t+1$ will cause consumption at time $t+1$ to deviate from consumption at time $t$. In other words, people adjust their consumption instantly when they learn any news about changes in future income. They make no further adjustments when the changes actually happen.

According to equation (3), changes in consumption are determined by innovations in expectations about future income. Therefore, modeling the income process is crucial for predicting consumption choices and SWB. Following a formulation used widely in the literature, we define the income process as the sum of a random walk and white noise (Meghir and Pistaferri, 2011):

$$
\begin{gathered}
x_{t}=x_{t}^{P}+\delta_{t}, \\
x_{t}^{P}=x_{t-1}^{P}+\eta_{t} .
\end{gathered}
$$


For all $\mathrm{s}$ and $\mathrm{t}, \delta_{s}$ and $\eta_{t}$ are independent. The appeal of the above income process is that it helps us to distinguish between the impact of transitory income shocks (defined as $\delta_{t}$ ) and permanent income shocks (defined as $\left.\eta_{t}\right) .^{6}$

By substituting (4) and (5) into (3), we get the following expression for changes in consumption:

$$
c_{t+1}-c_{t}=\eta_{t+1}+\frac{r}{1+r} \delta_{t+1}
$$

Since $r>0, \frac{r}{1+r}<1$. In words, the marginal propensity to consume (MPC) is greater for a permanent income shock than for a transitory income shock.

Because of the equivalence result that consumption in any period equals expected consumption in future periods, it is straightforward to show that if we define subjective wellbeing to be the sum of current and future discounted utility, the relative impacts of permanent income shocks and transitory income shocks on changes in subjective well-being will be the same as their relative impacts on changes in consumption (Appendix 2). In fact, using this definition of well-being, the qualitative result that permanent income shocks should have a greater impact than transitory income shocks on subjective well-being (defined as current plus future discounted utility) does not require that we assume quadratic utility. In Appendix 4, we prove that this prediction also holds if we assume constant relative risk aversion (CRRA).

\section{Empirical Strategy}

As mentioned earlier, one of the difficulties in identifying different types of income shocks is that consumers generally have "superior information" to econometricians. We follow earlier studies that use responses to questions about subjective expectations to

\footnotetext{
${ }^{6}$ We consider the implications of assuming a more general ARMA $(p, q)$ income process in Appendix 3.
} 
overcome this problem and distinguish permanent income shocks from transitory income shocks.

The income process described in equations (4) and (5) can be rewritten as follows:

$$
x_{t+1}=x_{t}+\eta_{t+1}+\delta_{t+1}-\delta_{t}
$$

An unanticipated income shock at time $t+1$ can be identified by the difference between income realizations and subjective income expectations. That is

$$
x_{t+1}-E\left(x_{t+1} \mid \Omega_{t}\right)=\eta_{t+1}+\delta_{t+1} .
$$

$E\left(x_{t+1} \mid \Omega_{t}\right)$ is the subjective expectation of income at time $t+1$ based on the individual's information set $\Omega_{t}$ at time $\mathrm{t}$, which we can also write as $E_{t}\left(x_{t+1}\right)$. The permanent income shock at time $t+1$ can be defined as follows:

$$
E\left(x_{t+2} \mid \Omega_{t+1}\right)-E\left(x_{t+1} \mid \Omega_{t}\right)=\eta_{t+1} .
$$

The transitory income shock can be identified from (7) and (8) as follows:

$$
x_{t+1}-E\left(x_{t+2} \mid \Omega_{t+1}\right)=\delta_{t+1} .
$$

We test two sets of working hypotheses. First, as indicated by equations (3), only unexpected income innovations will affect the optimal choice of consumption, and therefore well-being. Expected income changes have no effect on well-being. To conduct an empirical test of this prediction, we can specify the following reduced form model:

$$
s_{i, t+1}=\beta_{0}+\beta_{1} s_{i, t}+\beta_{2}\left[x_{i, t+1}-E_{t}\left(x_{i, t+1}\right)\right]+\beta_{3} E_{t}\left(x_{i, t+1}\right)+\psi Z_{i, t+1}+\zeta_{i, t+1},
$$

where $s_{i, t+1}$ is the well-being of individual $i$ at time $t+1, Z_{i, t+1}$ contains other covariates affecting well-being, and $\zeta_{i, t+1}$ is the error term. Rather than define the dependent variable as the change $s_{i, t+1}-s_{i, t}$, we put $s_{i, t}$ on the right hand side to control for expected state dependence due to mean reversion given the fixed scale for reporting SWB. The hypotheses are that $\beta_{2}>0$ and $\beta_{3}=0$.

Another implication of the rational expectation-permanent income hypothesis (RE-PIH), as implied by equation (6), is that an unanticipated permanent income shock has a greater 
impact on well-being than a transitory income shock. We can test this using the following reduced form model:

$$
\begin{gathered}
s_{i, t+1}=\beta_{0}^{\prime}+\beta_{1}^{\prime} s_{i, t}+\beta_{4}\left[E_{t+1}\left(x_{i, t+2}\right)-E_{t}\left(x_{i, t+1}\right)\right]+\beta_{5}\left[x_{i, t+1}-E_{t+1}\left(x_{i, t+2}\right)\right] \\
+\psi^{\prime} Z_{i, t+1}+\zeta_{i, t+1}^{\prime},
\end{gathered}
$$

Our hypotheses is that $\beta_{4}>\beta_{5}$.

In our data, subjective income expectations are measured as the household's expected relative income (and wealth) position in the village while the income realization is measured as the log of household income per capita (measurement explained in more detail in section 4). To make the actual and relative income measures more comparable, we convert household income per capita into a measure of relative income status in the village by ranking it among the sampled households in each village. ${ }^{7}$ We then adjust our specification to accommodate the available measurements. Consider the following linear model of relative income position:

$$
r_{i, t}=\alpha_{0}+\alpha_{1} x_{i, t}+\alpha_{2} X_{j, t}
$$

where $r_{i, t}$ is the relative income position of individual $i$ at time $t$ in his or her village $j, x_{i, t}$ is the income realization of individual $i$ at time $t$, and $X_{j, t}$ is the average income of all villagers in village $j$. By construction, $\alpha_{1}>0$ and $\alpha_{2}<0$.

At time $t$, the expectation of individual $i$ of his relative income status at time $t+1$ can be written as follows:

$$
E_{i, t}\left(r_{i, t+1}\right)=\alpha_{0}+\alpha_{1} E_{i, t}\left(x_{i, t+1}\right)+\alpha_{2} E_{i, t}\left(X_{j, t+1}\right) .
$$

Expected income position is determined by one's expectation of own income and by one's expectation of average income in the village. By assuming $E_{i, t}\left(X_{j, t+1}\right)=E_{t}\left(X_{j, t+1}\right)$, or that villagers share the same information set about future economic status of village, we get:

$$
r_{i, t+1}-E_{i, t}\left(r_{i, t+1}\right)=\alpha_{1}\left[x_{i, t+1}-E_{i, t}\left(x_{i, t+1}\right)\right]+\alpha_{2} V_{j}
$$

\footnotetext{
${ }^{7}$ By the survey design, household were randomly chosen in the village. Replacement of household because of attrition in the second survey was based on rule of economic similarity. Hence the relative income position in the sampled household of the same village is unbiased measures of the income position in the village.
} 
where $V_{j}=X_{j, t+1}-E_{t}\left(X_{j, t+1}\right)$. The above equation indicates how unexpected income shocks are related to unexpected changes in the household's relative income status.

Substituting the above equation into (10), we derive our empirical regression model:

$$
s_{i, t+1}=\tilde{\beta}_{0}+\beta_{1} s_{i, t}+\tilde{\beta}_{2}\left[r_{i, t+1}-E_{i, t}\left(r_{i, t+1}\right)\right]+\tilde{\beta}_{3} E_{i, t}\left(r_{i, t+1}\right)+\psi Z_{i, t+1}+\tilde{V}_{j}+\zeta_{i, t+1},
$$

where $\tilde{\beta}_{2}=\frac{\beta_{2}}{\alpha_{1}}, \tilde{\beta}_{3}=\frac{\beta_{3}}{\alpha_{1}}, \tilde{\beta}_{0}=\beta_{0}-\alpha_{0} \tilde{\beta}_{3}$, and $\tilde{V}_{j}=-\alpha_{2}\left[\tilde{\beta}_{2} V_{j}+\tilde{\beta}_{3} E_{t}\left(X_{j, t+1}\right)\right]$. The testable hypotheses are $\tilde{\beta}_{2}>0$, and $\tilde{\beta}_{3}=0$. Similarly, we can use the following regression model to test the counterpart of model (11):

$$
\begin{gathered}
s_{i, t+1}=\beta_{0}^{\prime}+\beta_{1}^{\prime} s_{i, t}+\beta_{4}^{\prime}\left[E_{i, t+1}\left(r_{i, t+2}\right)-E_{i, t}\left(r_{i, t+1}\right)\right]+\beta_{5}^{\prime}\left[r_{i, t+1}-E_{i, t+1}\left(r_{i, t+2}\right)\right]+\mathrm{V}_{j}^{\prime} \\
+\psi^{\prime} Z_{i, t+1}+\zeta_{i, t+1}^{\prime}
\end{gathered}
$$

where $\beta_{4}^{\prime}=\frac{\beta_{4}}{\alpha_{1}}, \beta_{5}^{\prime}=\frac{\beta_{5}}{\alpha_{1}}, \mathrm{~V}_{j}^{\prime}=-\alpha_{2}\left[\beta_{4}^{\prime} E_{t+1}\left(X_{j, t+2}\right)-\beta_{4}^{\prime} E_{t}\left(X_{j, t+1}\right)+\beta_{5}^{\prime} V_{j}\right] .{ }^{8}$ The assumption to be tested is $\beta_{4}^{\prime}>\beta_{5}^{\prime}$.

The control variables $Z_{i, t+1}$ are factors that may directly affect subjective well-being. They include age, age square, gender, marital status (married or not), education (five categories), household size, number of migrants in the household, share of household members aged younger than 18, share of household members aged older than 60 , year dummies. $\tilde{V}_{j}$ and $\mathrm{V}_{j}^{\prime}$ are absorbed by village dummies. Because the relative income measure is based on a question that refers to both income and wealth, we also add control variables for wealth to isolate the impacts of relative income. The wealth variables include log of housing value per capita, log of livestock value per capita, and a set of dummies for whether the household owns different consumer durables, and are included in all regressions with selfreported income variables.

\footnotetext{
${ }^{8}$ The expectation of future income may reflect life-time pattern in income which usually appears to be inverse U-shaped. We therefore adjust the change in expectation of future income by age and age square. Moreover, we control for the interaction of age and age square with gender and education separately, as well as village fixed effect. The former is to capture any changes of expectation because of structure difference of life time income profile over gender or education categories. The latter is to control for any common trend of income profile over time in the same village. The results are very similar, and are available upon request.
} 
A final measurement issue is possible reporting biases in answering questions about expectations for the future. For instance, optimistic (pessimistic) people may be happier (sadder) and also predict higher (lower) relative incomes in the future. To control for such outlook bias, we adjust the expectation of future income position in the village by a measure of individual-specific outlook bias, which we estimate as the difference between actual income rank (calculated from income measurement) and self-reported income rank in the village in the baseline year 2006. The results are not sensitive to this adjustment.

\section{Data}

The data used in this study are from the Chinese Rural Residents Living and Health Survey, a longitudinal household survey of a stratified random sample of rural households in China. The survey was conducted in 2006 and 2009 in 64 villages in four counties, two in Shandong Province in Eastern China, one in Sichuan Province in Western China, and one in Anhui Province in Central China. Four townships were randomly selected in each county, four villages were randomly selected in each town, and households were randomly sampled in each village. Overall, 1810 households were surveyed in 2006 and 1499 households (83\%) were successfully re-interviewed in 2009.

Only individuals aged 18 to 60 who live in the household or whose official residential registration is in the household were eligible to answer the questions on subjective relative income. The total number of such individuals in the 1499 households surveyed in both years was 3232, among which 983 people actually answered the questions on subjective relative income in both years. Many household members migrated or were not at home (and so de facto were not members of the household) in at least one of the survey years. ${ }^{9}$ Another 23

\footnotetext{
${ }^{9}$ Many household members were not at home when the survey was being conducted. Among the 2249 individuals who were eligible but didn't answer the questions on subjective relative income in one of the years, $1011(45 \%)$ were migrants and not living at home at the time of the survey, while others were at school or in their workplace at the time of the survey.
} 
respondents had incomplete data on the global life satisfaction questions and/or other control variables. Thus, our sample for analysis is comprised of 960 individuals living in 780 households who have complete data for both years. ${ }^{10}$ We use the inverse probability weighting (IPW) method proposed by Wooldridge (2002) to adjust for bias associated with selection and attrition of the sample. ${ }^{11}$

We use global life satisfaction as our measure of SWB. In the survey, people are asked "Generally speaking, are you satisfied with your life?". There are five possible answers: 1 very dissatisfied; 2 dissatisfied; 3 just so so; 4 satisfied; and 5 very satisfied. This life satisfaction measure has been used in a large number of studies and is an important dimension of well-being (Benjamin et al., 2014) which has been found to be correlated with socio-economic conditions such as job status, environment, and health (Winkelmann et al, 1998; Carroll et al., 2009; Deaton, 2008). Global life satisfaction covers a wider time span and is more stable than other SWB measures such as affect or experienced well-being (Kahneman and Deaton, 2010) $)^{12}$.

\footnotetext{
${ }^{10}$ Among the 780 households, 601 households have one observation in our panel analysis, 178 households have 2 observations, and 1 household has 3 observations. In all regressions standard error are clustered in household for possible correlation in SWB between household members.

${ }^{11}$ We first estimate a probit model for selecting into complete the questionnaire on global life satisfaction and subjective income positions among eligible household members in year 2006, and then estimate another probit model for the attrition of the selected sample. The predicted probability of selection was multiplied by the probability of attrition. Then the inverse of the product was used as weights in all analyses. In both probit regressions, we control for age, age squared, gender, dummies for marital status, education categories, household size, number of migrants in the household, share of family members aged less than 18, share of family members older than 60, share of family members be male, be married, with education of primary school, middle school, high/vocational school, college or above, log of household income per capita, log of house value per capita, log of value of livestock per capita, dummies of a couple of durables (large furnisher, bicycler, motorbike, electric battery vehicle, radio/recorder, black and white TV, color TV, telephone, mobile phone, audiovisual products, refrigerator, air conditioning, gas stove, sewing machine, camera, washing machine, electric/solar water heater, computer, dispenser, microwave, agricultural motor vehicle, and car/truck), and village dummies.

${ }^{12}$ In the survey, the question of global life satisfaction was asked at the beginning of the third part in the questionnaire following general household questions and the basic demographic questions of household members. Therefore, the answers to the global life satisfaction is less likely to be influenced by the order of questions, as criticized by Kahneman et al. (2006) which is so called "focusing illusion".
} 
As noted above, we construct two sets of income measurements from the survey. One is objective income, measured by household income per capita. ${ }^{13}$ The other is subjective income, from self-reports of the household's relative economic position in the village at the time of the survey, as well as the expected income position in the village three years later (see Appendix 1 for specific wording of the questions).

Table 1 reports descriptive statistics for the variables used in the analysis among the balanced sample. The means and standard deviations are adjusted by IPW. As indicated above, the measure of global life satisfaction ranges from 1 to 5; the higher the value, the more satisfied is the individual. The average global life satisfaction was 3.81 in the year 2006 and declined slightly in year 2009. Comparing the two sets of income measures, we find that expectations of future income position are on average greater than current income position. As expected, the average age of the sample increased by three, while gender, marital status, and education were generally unchanged between the two years. Household size also on average remains unchanged, while the number of migrants in the household decreased. The average household income per capita increased by $26 \%$ in real terms over the 3 -year time period (using provincial rural CPI to correct for inflation). These simple statistics suggest that, on average, the increase in income was not associated with an increase in SWB over time. We dig deeper into the relationship between income and SWB below.

\section{Results}

We first replicate previous specifications used to test relationship between income and SWB. Results are reported in the first two columns of Table 2. The first column reports the results of the pooled OLS estimation, which includes the main covariate log of household

\footnotetext{
${ }^{13}$ The household income measures the income of the household in previous year of each survey. It is the summarization of income from various sources, including revenue from agriculture, forestry, animal husbandry, fishery and other business, wage, asset revenue, transfers, remittance, and others. We exclude migrants for calculating per capita income in households.
} 
income per capita and controls for individual and household characteristics. As shown, SWB increases significantly with income. More specifically, the coefficient of 0.154 implies that a 10 percent increase in income is associated with an increase in SWB of 0.0154 (or 0.018 standard deviations measured in the baseline year). The results in column (2) control for individual fixed effects. The coefficient on log income per capita decreases substantially to 0.074 and is no longer statistically significantly different from zero. The results are consistent with previous findings of other studies that the relationship between income and SWB is positive and significant in cross-sectional analysis, but the association disappears or is much weaker in panel analysis (Ferrer-i-Carbonell and Frijters, 2004; Winkelmann et al., 1998). The coefficients of other covariates are generally consistent with expectations. Life satisfaction has a U-shaped relationship with age in cross-section. Females and more educated persons express greater life satisfaction. Those living in households with more old people are less satisfied. Conditioning on other factors, life satisfaction declines from 2006 to 2009.

To test the relative income hypothesis, we include the average income of reference groups in regressions (3) and (4). Studies have suggested that fellow villagers of rural households are a natural reference group in rural China (Knight et. al., 2009; Mangyo and Park, 2011). The relative income hypothesis predicts that people's life satisfaction decreases with income of the reference group. But our cross-sectional regression finds that the coefficient is zero. Moreover, according to the RIH, failing to control for income of the reference group is likely to lead to a weaker coefficient on income in panel analysis. However, our data suggests that even after we control for average income in the village, the coefficient on individual income is still substantially smaller than in cross-sectional analysis (see results in column 3 and 4). Thus, the predictions of the RIH are not supported by our data. 
Next, we turn to the two sets of working hypotheses based on the RE-PIH described in Section 3 that examine the impact on SWB of unexpected versus anticipated income, and unexpected permanent versus transitory shocks. The results of our tests of the first set of hypotheses are reported in Table 3, in which we control for lagged global life satisfaction, current and baseline values for variables of individual and household characteristics, as well as village fixed effects. In this model, village fixed effects absorb all unobserved village characteristics. As shown in the results when each income measure is entered by itself and presented in columns (1) and (2), unexpected income shocks are positively correlated with SWB, while the coefficient on expected income is close to zero. In the specification including both income measures whose results are reported in column (3), the coefficient on the unexpected income shock increases and remains significant, while the coefficient on expected income also increases but still is not significantly different from zero. ${ }^{14}$ An unexpected income shock that increases the relative income rank in the village by one decile (10 percentage points) increases subjective well-being by 0.028 (or 0.033 standard deviations in the baseline year).

The results of testing for different effects of permanent and transitory income shocks are reported in Table 4. Results reported in columns (1) and (2) including each income measure separately suggest that permanent income shocks have positive and significant effects on SWB, while the effect of transitory income shocks are much smaller and not significantly different from zero. The results including both income measures reported in column (3) confirm this difference. A permanent income shock that increases the relative income rank in the village by one decile (10 percentage points) increases subjective wellbeing by 0.039 , compared to just 0.013 (and not significant) for a transitory shock. In

\footnotetext{
${ }^{14}$ However, in this case we cannot reject hypothesis that the effect of the two types of income are the same. The $p$ value of Wald test is 0.5183 . Positive effects of expected income changes could occur if households are credit constrained (more below) or if preferences are present-biased.
} 
addition, the $p$ value of the Wald test leads us to reject the hypothesis that $\beta_{4}^{\prime} \leq \beta_{5}^{\prime}$ at the $5 \%$ significance level.

\section{Extensions}

\section{Credit Constraints}

Thus far we have assumed perfect credit markets whereby individuals can borrow and save freely at an exogenous interest rate. In reality, this is unlikely to hold true for many households even in developed countries but especially in developing countries. Empirical studies in developing countries have found different response patterns of consumption with respect to positive and negative transitory income shocks, and for low-wealth and highwealth households (Morduch, 1990; Fafchamps and Lund, 2003; Rosenzweig and Wolpin, 1993; Fafchamps et al., 1998; Cameron and Worswick, 2003; Rosenzweig, 2001; Meng, 2003). We investigate the role of liquidity constraints by distinguishing positive and negative transitory income shocks and test for their effects on the well-being of households with low wealth and high wealth.

We extend the benchmark model by investigating how well-being is affected by permanent and transitory income shocks when households are credit constrained. ${ }^{15}$ Now, households are subject to an additional liquidity constraint $(1+r) w_{t}+x_{t}-c_{t} \geq 0$. We focus on cases when $E_{t-1}\left[(1+r) w_{t}+x_{t}-c_{t}\right] \geq 0$, or equivalently $E_{t-1}\left(w_{t+1}\right) \geq 0$. In words, based on information available at time $t-1$, the liquidity constraint is not binding. Adjustment in consumption can be expressed as a function of the permanent and transitory income shocks,

$$
c_{t}-c_{t-1}=\mu_{1} \eta_{t}+\mu_{2} \delta_{t}
$$

\footnotetext{
${ }^{15}$ Studies found response of consumption to a transitory income shocks is more sensitive than predicted in the standard model. For instance, Gertler and Gruber (2002) found illness is associated with significant fall in consumption in Indonesia. Cameron and Worswick (2003) found the role of saving is incomplete in allowing households to smooth consumption in the face of crop losses.
} 
As derived earlier, the policy function in the case of perfect credit markets is $\mu_{1}=1$ and $\mu_{2}=\frac{r}{1+r}$. Since optimal consumption adjusts one to one with permanent income shocks, the liquidity constraint $(1+r) w_{t}+x_{t}-c_{t} \geq 0$ is never binding. Therefore the first best solution can be achieved, and $\mu_{1}=1$ also holds for permanent income shocks even in the case of imperfect credit markets.

For transitory income shocks, we distinguish between positive and negative transitory income shocks. If the credit constraint is not initially binding, in the case of positive transitory income shocks the first best solution can always be achieved, and $\mu_{2}=\frac{r}{1+r}$ still holds. In the case of negative transitory income shocks, the first best solution can not always be achieved, since the liquidity constraint $(1+r) w_{t}+x_{t}-c_{t} \geq 0$ may be binding. For example, when $x_{t}$ decreases by amount $\left|\delta_{t}\right|$ because of a negative transitory shock, the optimal adjustment with perfect credit markets is to decrease consumption by the amount $\mathrm{r}\left|\delta_{t}\right| /(1+r)$ for each subsequent period. However, if the household cannot self-finance the negative transitory shock and the liquidity constraint is binding, then $\mu_{2}>\frac{r}{1+r}$. One extreme case is when $E_{t-1}\left(w_{t+1}\right)=0$, in which case $c_{t}$ needs to adjust one to one with the negative income shock $\left(\mu_{2}=1\right)$. The effects on consumption of a negative transitory income shock thus can be summarized as follows:

$$
\left\{\begin{array}{c}
\mu_{2}=1, \delta_{t}<0 \text { and } E_{t-1}\left(w_{t+1}\right)=0 \\
\frac{r}{1+r}<\mu_{2}<1, \delta_{t}<0 \text { and } 0<E_{t-1}\left(w_{t+1}\right)<\frac{\left|\delta_{t}\right|}{1+r} . \\
\mu_{2}=\frac{r}{1+r}, \delta_{t}<0 \text { and } E_{t-1}\left(w_{t+1}\right) \geq \frac{\left|\delta_{t}\right|}{1+r}
\end{array}\right.
$$

In the extreme case where $\delta_{t}<0$ and $E_{t-1}\left(w_{t+1}\right)=0$, the first best consumption choice is not achievable, implying that welfare is worse compared with that achieved in the model with perfect credit markets. The credit constraint introduces additional variation in consumption, and leads to a welfare loss equal to $b \beta \delta_{t}^{2} / 2$ (see Appendix 5 for derivation). 
The marginal effect of a negative transitory income shock on well-being is $\frac{r}{1+r} \frac{u^{\prime}\left(c_{t}^{*}\right)}{1-\beta}+b \beta\left|\delta_{t}\right|$, where $c_{t}^{*}$ is the first best choice of consumption with perfect credit markets. The effect is greater than the marginal effect of the positive transitory income shock on well-being, but is smaller than the marginal effect of the permanent income shock on well-being when $\left|\delta_{t}\right|<$ $\frac{u^{\prime}\left(c_{t}^{*}\right)}{b(1-\beta)}$ (and larger when the inequality sign is reversed).

Since the welfare loss is the greatest in the extreme case, it provides an upper bound for the marginal effect of a negative transitory income shocks on well-being. For households that are partially self-financing, the predictions are similar but the effects may be smaller in magnitude.

To sum up, when the credit market is imperfect, theoretical predictions about the adjustment of consumption to income shocks differs from that of the benchmark model when households are unable to finance the same level of consumption as that predicted by a model with perfect capital markets. The welfare implications are complicated. When the credit constraint binds, the marginal effect on welfare of a negative transitory income shock can either be greater or smaller than that of a permanent income shock, depending on the magnitude of the negative transitory income shocks and households' capability to selffinance. The marginal effect on welfare of a positive transitory income shock is always smaller than that of a permanent income shock.

The results of empirical tests of these predictions are reported in Table 5. Regression results reported in Column (1) are based on a model that allows for asymmetric effects of positive and negative income shocks:

$$
\begin{gathered}
s_{i, t+1}=\beta_{0}+\beta_{1} s_{i, t}+\beta_{4}^{\prime} \widetilde{\varepsilon_{t}}+\beta_{5 \_n e g}^{\prime} \widetilde{\delta_{t}} \cdot 1\left(\widetilde{\delta_{t}}<0\right)+\beta_{5 \_p s}^{\prime}{\widetilde{\delta_{t}}}_{t} \cdot 1\left(\widetilde{\delta_{t}}\right. \\
>0)+\gamma_{j}+\zeta Z_{i, t+1}+\zeta_{i, t+1}
\end{gathered}
$$


where $\widetilde{\varepsilon_{t}}=\left[E_{i, t+1}\left(R_{i j, t+2}\right)-E_{i, t}\left(R_{i j, t+1}\right)\right], \widetilde{\delta_{t}}=\left[R_{i j, t+1}-E_{i, t+1}\left(R_{i j, t+2}\right)\right]$, and $1(\cdot)$ is an index function. The effect of permanent income shocks on SWB is nearly the same as that in Table 4. Interestingly, we find that the marginal effect on SWB is positive and significantly different from zero for negative transitory income shocks. That is, people are significantly worse off even when the negative income shock is transitory. This suggests that on average people are unable to efficiently smooth consumption when they face negative transitory income shocks. The results also indicate there is no significant change in SWB for positive transitory income shocks. ${ }^{16}$ Wald tests find that the coefficient on the permanent income shock is significantly greater than that on the positive transitory income shock; while it is not significantly different from that of a negative transitory income shock.

Studies have found that assets, such as livestock, can serve as a buffer stock in rural households of developing countries (Rosenzweig and Wolpin, 1993; Fafchamps et al., 1998). Moreover, people with greater wealth are more likely to have access to credit markets if assets can be used as collateral (Jalan and Ravallion, 1999). We use assets as a proxy for the likelihood of households being liquidity constrained and investigate the welfare implication of income shocks for subsamples with high and low assets. ${ }^{17}$ As shown in the regression results reported in Column (2) of Table 5, for individuals living in households with low assets, the marginal welfare impact of a negative transitory income shock is 0.045 , which is significantly different from zero. The interaction term between the dummy for high assets and the negative transitory income shock is -0.055 and significantly different from zero. The results suggest that for wealthy individuals the marginal effect of negative transitory income shock is close to zero. It justifies the theoretical prediction that transitory income shocks only

\footnotetext{
${ }^{16}$ De Neve et al. (2014) found that recessions have a greater impact on individual happiness than periods of growth, which they attribute to macroeconomic loss aversion.

${ }^{17}$ We construct a wealth index for each household by performing a principle-component factor analysis among a set of variables that measure household's assets. See footnote 12 for more details.
} 
have significant impacts on SWB when individuals face negative income shocks with limited credit.

\section{Finite Time Horizon.}

In the benchmark model, we assume the time horizon is infinite. Now we loosen the assumption by assuming the head of the household dies at age $A$ leaving no bequest. In this case,

$$
c_{t}-c_{t-1}=\eta_{t}+\tilde{\gamma} \delta_{t}
$$

where $\tilde{\gamma}=\frac{r}{1+r}\left[1-\left(\frac{1}{1+r}\right)^{A-a+1}\right]^{-1}$, and $a$ is the age of the household head at time $t$. Since $\tilde{\gamma}$ increases with $a$, one implication of the finite time horizon model is that the response of consumption to transitory income shock is greater for household with older head. This relationship maps to the impact on well-being. More specifically, we have $\partial\left(\Delta v_{t}\right) / \partial \eta_{t}=$ $u^{\prime}\left(c_{t}\right) g(\beta ; a)$ and $\partial\left(\Delta v_{t}\right) / \partial \eta_{t}=\tilde{\gamma} u^{\prime}\left(c_{t}\right) g(\beta ; a)$, where $g(\beta ; a)=\left(1-\beta^{A-a+1}\right)(1-\beta)^{-1}$, and $\tilde{\gamma} \leq 1$ (equality holds when $a=A$ ). Table 6 reports empirical results on testing the predictions among household with head of different age groups.

We divide the sample into two subgroups by the age of household head. For those in households with heads aged between 21 and 45 years old, we find the marginal effect of transitory income shocks is not significantly different from zero. The effect of a permanent income shock is positive, but not statistically significantly either. In contrast, for individuals in households with heads who are older, the marginal effect of a transitory income shock is positive and significantly different from zero. This finding confirms the theoretical prediction that older people are more affected by transitory income shocks given their shorter time horizon for smoothing consumption. The marginal effect of a permanent income shock is also significantly greater than zero. The Wald tests suggest that for both groups of people, the 
marginal effect of a permanent income shock on SWB is greater than that of a transitory income shock.

\section{Measurement Error}

One common explanation for the weaker correlation between SWB and income in panel analysis is that the signal to noise ratio is lower in panel regressions than in crosssectional regressions (Layard et al., 2008). The first difference eliminates most of the signal in measured income, while errors dominate the variation used for identification. Although we don't have an obvious instrument to deal with the measurement error problem, we do not believe that the measurement error is likely to explain our findings. First of all, in our main analysis, income is measured in relative form and in deciles, so the errors in the measurement will be less serious than for self-reported income in monetary units. Secondly, if error dominates the signal in first differences, we would expect to find no significant correlation between SWB and unanticipated income shocks. However, we actually find that unanticipated income shocks significantly increase SWB. Similarly, the signal-error model can't explain the different effects on SWB of permanent and transitory income shocks. To sum up, although we can't exclude the possibility that there is measurement error in income, it appears unlikely to explain the different correlation between SWB and income using crosssectional and panel specifications.

\section{Explaining Differences in Cross-sectional and Panel Studies}

Consider the following two regression models:

$$
\begin{gathered}
s_{i t}=\phi_{0}+\phi_{1} x_{i t}+\Theta Z_{i t}+e_{i t}, \\
s_{i t}=\phi_{0}^{\prime}+\phi_{1}^{\prime} x_{i t}^{P}+\phi_{2}^{\prime} \delta_{i t}+\Theta^{\prime} Z_{i t}+e_{i t}^{\prime} .
\end{gathered}
$$


Equation (12) is a typical cross-sectional SWB regression equation, where $x_{i t}$ is the income of individual $i$ at time $t$, and $Z_{i t}$ is a set of control variables. As shown in equation (4), income can be defined to be the sum of transitory income shocks $\left(\delta_{i t}\right)$ and lifetime income at time $t\left(x_{i t}^{P}\right)$ (Hall and Mishkin, 1982). Thus, $x_{i t}=x_{i t}^{P}+\delta_{i t}$, and the relationship between the estimated $\hat{\phi}_{1}$ from equation (12) and the estimated $\hat{\phi}_{1}^{\prime}$ and $\hat{\phi}_{2}^{\prime}$ from equation (13) can be expressed as $\hat{\phi}_{1}=\omega_{c} \hat{\phi}_{1}^{\prime}+\left(1-\omega_{c}\right) \hat{\phi}_{2}^{\prime}$ where $\omega_{c}=\frac{\widehat{\sigma}_{p}+\widehat{\sigma}_{p \delta}}{\widehat{\sigma}_{x}}$ in the absence of control variables (see derivation in Appendix 6). Here, $\hat{\sigma}_{p}$ and $\hat{\sigma}_{x}$ are the sample variances of $x_{i t}^{P}$ and $x_{i t}$, and $\hat{\sigma}_{p \delta}$ is the sample covariance between $x_{i t}^{P}$ and $\delta_{i t}$.

Now, consider the following estimating equations using panel data:

$$
\begin{gathered}
\Delta s_{i t}=\lambda_{0}+\lambda_{1} \Delta x_{i t}+\Psi \Delta Z_{i t}+u_{i t}, \\
\Delta s_{i t}=\lambda_{0}^{\prime}+\lambda_{1}^{\prime} \eta_{i t}+\lambda_{2}^{\prime}\left(\delta_{i t}-\delta_{i(t-1)}\right)+\Psi^{\prime} \Delta Z_{i t}+u_{i t}^{\prime},
\end{gathered}
$$

where $\Delta x_{i t}$ is the change in income, which can be modeled as $\Delta x_{i t}=\delta_{i t}-\delta_{i(t-1)}+\eta_{i t}$ according to equations (4) and (5). Similarly, we have $\hat{\lambda}_{1}=\omega_{p} \hat{\lambda}_{1}^{\prime}+\left(1-\omega_{p}\right) \hat{\lambda}_{2}^{\prime}$, where $\omega_{p}=\frac{\widehat{\sigma}_{\eta}+\widehat{\sigma}_{\eta \Delta \delta}}{\widehat{\sigma}_{\Delta x}}$ in the absence of control variables, and $\hat{\lambda}_{1}, \hat{\lambda}_{1}^{\prime}, \hat{\lambda}_{2}^{\prime}, \widehat{\Psi}$, and $\widehat{\Psi}^{\prime}$ are ordinary least square estimators of regression equations (14) and (15). Here, $\hat{\sigma}_{\eta}$ and $\hat{\sigma}_{\Delta x}$ are the sample variances of $\eta_{i t}$ and $\Delta x_{i t}$, and $\hat{\sigma}_{\eta \Delta \delta}$ is the sample covariance between $\eta_{i t}$ and $\Delta \delta_{i t}$.

Table 7 reports the calibration of the parameters $\hat{\sigma}_{x}, \hat{\sigma}_{p}, \hat{\sigma}_{p \delta}, \hat{\sigma}_{\delta}, \hat{\sigma}_{\Delta x}, \hat{\sigma}_{\eta}, \hat{\sigma}_{\eta \Delta \delta}$ and $\hat{\sigma}_{\Delta \delta}$ from the data. The variance of the transitory income shock $\left(\hat{\sigma}_{\delta}\right)$, permanent income shock $\left(\hat{\sigma}_{\eta}\right)$, and lifetime income components $\left(\hat{\sigma}_{p}\right)$ are $13.67,5.83$ and 11.32 separately. Calculation of $\omega_{c}$ and $\omega_{p}$ from the equations $\omega_{c}=\frac{\widehat{\sigma}_{p}+\widehat{\sigma}_{p \delta}}{\widehat{\sigma}_{x}}$ and $\omega_{p}=\frac{\widehat{\sigma}_{\eta}+\widehat{\sigma}_{\eta \Delta \delta}}{\widehat{\sigma}_{\Delta x}}$ reveal that $\omega_{c}=0.347$ and $\omega_{p}=0.107$ (column 1), providing strong evidence that $\omega_{c}>\omega_{p}$. This finding provides strong support for our contention that cross-sectional regressions put a significantly greater weight on variation in the permanent component of income than panel regressions. 
Adding control variables $\mathrm{Z}$ slightly complicates the formulas for calculating $\omega_{c}$ and $\omega_{p}$, requiring them to account for possible changes in the coefficients on the controls across different specifications. The adjusted formulas are $\omega_{c}=\frac{\widehat{\sigma}_{p}+\widehat{\sigma}_{p \delta}}{\widehat{\sigma}_{x}}+\frac{\left(\widehat{\Theta}^{\prime}-\widehat{\Theta}\right) \cdot \widehat{\gamma}}{\widehat{\phi}_{1}^{\prime}-\widehat{\phi}_{2}^{\prime}}$ and $\omega_{p}=$ $\frac{\widehat{\sigma}_{\eta}+\widehat{\sigma}_{\eta \Delta \delta}}{\widehat{\sigma}_{\Delta x}}+\frac{\left(\widehat{\Psi}^{\prime}-\widehat{\Psi}\right) \cdot \hat{\tau}}{\widehat{\lambda}_{1}^{\prime}-\widehat{\lambda}_{2}^{\prime}}$, where $\hat{\gamma}$ and $\hat{\tau}$ are the ordinary least squares coefficients from the regressions $Z_{i t}=\gamma_{0}+\gamma x_{i t}+\epsilon_{i t}^{\gamma}$ and $\Delta Z_{i t}=\tau_{0}+\tau \Delta x_{i t}+\epsilon_{i t}^{\tau}$. We do not expect these adjustments to strongly influence the gap between $\omega_{c}$ and $\omega_{p}$ since we do not have any reason to expect the coefficients on the controls to vary differently across specifications in the cross-sectional and panel regressions. Using the adjusted formulas, we find that $\omega_{c}=0.308$ and $\omega_{p}=0.087$ (column 2 ), which are both slightly smaller than the unadjusted estimates. The conclusion that $\omega_{c}>\omega_{p}$ remains unchanged.

Assuming $\left\{\eta_{t}\right\}$ and $\left\{\delta_{t}\right\}$ are mutually independent over time, we have $\frac{\partial x_{t}^{P}}{\partial \eta_{t}}=1$ and $\frac{\partial \Delta \delta_{t}}{\partial \delta_{t}}=1 .{ }^{18}$ Since $V_{t-1}$ is independent of $\eta_{t}$ according to the rational expectations hypothesis, $\frac{\partial \Delta V_{t}}{\partial \eta_{t}}=\frac{\partial V_{t}}{\partial \eta_{t}}=\frac{\partial V_{t}}{\partial x_{t}^{P}} \frac{\partial x_{t}^{P}}{\partial \eta_{t}}=\frac{\partial V_{t}}{\partial x_{t}^{P}}$. That is, the marginal effect of lifetime income on well-being is the same as the effect of permanent income shocks on the change in wellbeing, or $\phi_{1}^{\prime}=\lambda_{1}^{\prime}$. By a similar logic, we also expect that $\phi_{2}^{\prime}=\lambda_{2}^{\prime}$. As derived above, $\hat{\phi}_{1}$ and $\hat{\lambda}_{1}$ can be interpreted as the weighted average of the effects of permanent and transitory income shocks. We have shown that the marginal effect of a permanent income shock on well-being should be greater than that of a transitory income shock. Given that $\omega_{c}>\omega_{p}$, we posit that $\hat{\phi}_{1}>\hat{\lambda}_{1}$.

\footnotetext{
${ }^{18}$ To make this more clear, we rewrite the lifetime component of income at time $t$ as $x_{t}^{P}=\eta_{t}+\eta_{t-1}+\cdots+$ $\eta_{1}+\omega_{0} . \eta_{t}$ is a permanent income shock at time $t$. It is a component of lifetime income at time $t$, in the sense that it is a component of income at time $t$, as well as of income in all future periods. Similarly, $\eta_{1}, \cdots, \eta_{t-1}$ are also components of lifetime income at time $t . \omega_{0}$ is an initial lifetime component, which is assumed to be determined by observable characteristics $X$ in the form $\omega_{0}=\Gamma X$. We have $\frac{\partial x_{t}^{P}}{\partial \eta_{t}}=1$, when $\left\{\eta_{t}\right\}$ is independent over time.
} 
This is verified in the regression results reported in columns (1) and (3) of Table 8, which shows that $\hat{\phi}_{1}>\hat{\lambda}_{1} \cdot{ }^{19}$

Table 8 also reports the OLS estimation results of the regression models (13) and (15). Comparing the coefficients in columns (2) and (4), we find that the coefficients on lifetime income and permanent income shocks are almost the same, while the coefficients on transitory income shocks and on changes in transitory income shocks differ a bit. Formal Wald tests on $\phi_{1}^{\prime}=\lambda_{1}^{\prime}$ and $\phi_{2}^{\prime}=\lambda_{2}^{\prime}$ suggest that we cannot reject these null hypotheses at the $10 \%$ significance level. We further test the hypotheses that $\phi_{1}^{\prime}>\phi_{2}^{\prime}$ and $\lambda_{1}^{\prime}>\lambda_{2}^{\prime}$ using within equation comparisons of coefficients. The $\mathrm{p}$ value of the Wald tests on $\phi_{1}^{\prime} \leq \phi_{2}^{\prime}$ and $\lambda_{1}^{\prime} \leq \lambda_{2}^{\prime}$ are 0.108 and 0.054 separately.

\section{Conclusion}

In this study, we propose a new explanation for the inconsistent relationship between income and SWB found in previous cross-sectional and panel studies. We argue that income only significantly impacts well-being if it reflects differences in permanent income. Our benchmark model of welfare analysis based on the RE-PIH suggests individuals' well-being changes only when they encounter unexpected income shocks, and that the marginal welfare effect of a permanent income shock is greater than that of a transitory income shock. These predictions are confirmed by our analysis of panel data from China. Thus, the different relationships found in the literature, as well as in our study, reflect differences in the type of variation in income used for identification in cross-sectional and panel analysis. The share of the variation in total income accounted for by the lifetime component of income in crosssectional comparisons, is found to be greater than the share of the variation in income changes accounted for by unexpected permanent income shocks in panel specifications. Since

\footnotetext{
${ }^{19}$ These equations use the relative income variables to be comparable with the specifications that distinguish between expected and unexpected shocks, and between permanent and transitory income shocks.
} 
the marginal welfare impact of the permanent income shock is greater than that of the transitory income shock, we expect a much more significant correlation between income and SWB in cross-section analysis than in panel analysis. Our empirical results support these predictions. 


\section{References}

Benjamin, Daniel J., Ori Heffetz, Miles S. Kimball, and Nichole Szembrot. 2014. "Beyond Happiness and Satisfaction: Toward Well-Being Indices Based on Stated Preference." American Economic Review.104(38): 2698-2735.

Blanchflower, David G., and Andrew J. Oswald. 2004. "Well-being Over Time in Britain and the USA," Journal of Public Economics 88: 1359-1386.

Blundell, Richard, Hamish Low, Ian Preston. 2004. "Income Risk and Consumption Inequality: A Simulation Study," The Institute for Fiscal Studies working paper, WP04/26.

Blundell, Richard, Luigi Pistaferri, and Ian Preston. 2008. "Consumption Inequality and Partial Insurance,"American Economic Review 98(5):1887-1921.

Browning, Martin, and Dolores Collado. 2001. "The Response of Expenditures to Anticipated Income Changes: Panel Data Estimates," American Economic Review 91(3): 681-692.

Cameron, Lisa, and Christopher Worswick. 2003. "The Labor Market as a Smoothing Device: Labor Supply Responses to Crop Loss," Review of Development Economics 7(2): 327-341.

Carroll, Nick, Paul Frijters, and Michael A. Shields. 2009. "Quantifying the Costs of Drought: New Evidence from Life Satisfaction Data," Journal of Population Economics 22(2):445-461.

Clark, Andrew E., FabriceEtilé, Fabien Postel-Vinay, Claudia Senik, and Karine Van der Straeten. 2005. "Heterogeneity in Reported Well-Being: Evidence from Twelve European Countries," Economic Journal 115(502): C118-132.

Clark, Andrew E., Paul Frijters, and Michael A. Shields. 2008. "Relative Income, Happiness, and Utility: An Explanation for the Easterlin Paradox and Other Puzzles," Journal of Economic Literature 46 (1): $95-144$.

Deaton, Angus. 2008. "Income, Health, and Well-Being around the World: Evidence from the Gallup World Poll," Journal of Economic Perspectives 22(2):53-72.

De Neve, Jan-Emmanuel, George W. Ward, Femke De Keulenaer, Bert Van Landeghem, Georgios Kavetsos, and Michael I. Norton. 2014. "Individual Experience of Positive and Negative Growth is Asymmetric: Evidence from Subjective Well-being Data," LSE Centre for Economic Performance, Discussion Paper No. 1304.

Di Tella, Rafael, John Haisken-De New, and Robert MacCulloch. 2010. "Happiness Adaptation to Income and to Status in an Individual Panel," Journal of Economic Behavior and Organization 76(3):834-852.

Di Tella, Rafael, and Robert J. MacCulloch. 2006. "Some Uses of Happiness Data in Economics," Journal of Economic Perspectives 20(1): 25-46.

Di Tella, Rafael, Robert J. MacCulloch, and Andrew J. Oswald. 2003. "The Macroeconomics of Happiness," Review of Economics and Statistics 85(4): 809-827.

Duesenbetry, James S.. 1949. Income, Savings, and the Theory of Consumer Behaviour. Cambridge, Mass.: Harvard University Press. 
Easterlin, Richard A.. 1973. "Does Money Buy Happiness?” The Public Interest 30: 3-10.

Easterlin, Richard A.. 1974. "Does Economic Growth Improve the Human Lot? Some Empirical Evidence," in Paul A. David and Melvin W. Reder, eds., Nations and Households in Economic Growth: Essays in Honour of Moses Abramovitz, New York: Academic Press, Inc.

Easterlin, Richard A.. 1995. "Will Raising the Incomes of All Increase the Happiness of All?" Journal of Economic Behavior and Organization 27: 35-47.

Easterlin, Richard A.. 2001. "Income and Happiness: Towards a Unified Theory," The Economic Journal 111(473):465-484.

Fafchamps, Marcel, Christopher Udry, and Katherine Czukas. 1998. "Drought and Savings in West Africa: Are Livestock a Buffer Stock?" Journal of Development Economics 55(2):273-305.

Fafchamps, Marcel, and Susan Lund. 2003. "Risk-sharing Networks in Rural Philippines," Journal of Development Economics 71(2): 261-287.

Ferrer-i-Carbonell, Ada, and Paul Frijters. 2004. "How Important Is Methodology for the Estimates of the Determinants of Happiness?” The Economic Journal 114(497): 641-659.

Flavin, Marjorie A.. 1981. "The Adjustment of Consumption to Changing Expectations about Future Income," Journal of Political Economy 89(5):974-1009.

Flavin, Marjorie A.. 1993. "The Excess Smoothness of Consumption: Identification and Interpretation," Review of Economic Studies 60(3): 651-666.

Frey, Bruno S., and Alois Stutzer. 2002. "What Can Economists Learn from Happiness Research?" Journal of Economic Literature, 40(2): 402-435.

Friedman, Milton. 1957. A Theory of the Consumption Function. Princeton: Princeton University Press.

Gardner, Jonathan, and Andrew J. Oswald. 2007. "Money and Mental Wellbeing: A Longitudinal Study of Medium-Sized Lottery Wins," Journal of Health Economics 26(1): 49-60.

Gertler, Paul, and Jonathan Gruber. 2002. "Insuring Consumption against Illness," American Economic Review 92(1):51-70.

Graham, Carol, and Stefano Pettinato. 2004. Happiness and Hardship: Opportunity and Insecurity in New Market Economies. Washington, D.C.: Brookings Institution Press.

Hall, Robert E.. 1978. "Stochastic Implications of the Life-Cycle Permanent Income Hypothesis: Theory and Evidence," Journal of Political Economics 86(6): 971-987.

Hall, Robert E., and Frederic S Mishkin. 1982. "The Sensitivity of Consumption to Transitory Income: Estimates from Panel Data on Households," Econometrica 50(2): 461-481.

Hayashi, Fumio. 1985. "The Permanent Income Hypothesis and Consumption Durability: Analysis Based on Japanese Panel Data," Quarterly Journal of Economics 100(4):1083-1113.

Jalan, Jyotsna, and Martin Ravallion. 1999. "Are the Poor Less Well Insured? Evidence on Vulnerability to Income Risk in Rural China," Journal of Development Economics 58(1):61-81. 
Jappelli, Tullio, and Luigi Pistaferri. 2010. "The Consumption Response to Income Changes," Annual Review of Economics 2: 479-506.

Kahneman, Daniel and Angus Deaton. 2010. "High Income Improves Evaluation of Life but not Emotional Well-Being," Proceedings of the National Academy of Sciences of the United States of America 107(38): 16489-16493.

Kahneman, Daniel, Alan B. Krueger, David Schkade, Norbert Schwarz, Arthur A. Stone. 2006. "Would You Be Happier If You Were Richer? A Focusing Illusion," Science 312: 1908-1910.

Kaufmann, Katja, and Luigi Pistaferri. 2009. "Disentangling Insurance and Information in Intertemporal Consumption Choices," American Economic Review, Papers and Proceedings 99(2): 387-392.

Knight, John, Lina Song, and Ramani Gunatilaka. 2009. "Subjective Well-being and its Determinants in Rural China," China Economic Review 20(4): 635-649.

Layard, Richard, Guy Mayraz and Stephen J. Nickell. 2008. "The Marginal Utility of Income," Journal of Public Economics 92(8):1846-1857.

Lelkes, Orsolya. 2006. "Tasting Freedom: Happiness, Religion and Economic Transition," Journal of Economic Behavior and Organization 59(2): 173-194.

Luttmer, E. F. P. 2005. "Neighbors as Negatives: Relative Earnings and Well-being," The Quarterly Journal of Economics 120(3): 963-1002.

Mangyo, Eiji, and Albert Park. 2011. "Relative Deprivation and Health: Which Reference Groups Matter?" Journal of Human Resources 46(3): 459-481.

Meghir, Costas, and Luigi Pistaferri. 2011. "Earnings, Consumption and Life Cycle Choices." Handbook of Labor Economics 4: 773-854.

Meng, Xin. 2003. "Unemployment, Consumption Smoothing, and Precautionary Saving in Urban China," Journal of Comparative Economics 31(3): 465-485.

Meyer, Bruce D., and Wallace K.C. Mok. 2013. "Disability, Earnings, Income and Consumption," NBER Working Papers 18869.

Morduch, Jonathan. 1990. Risk, Production and Saving: Theory and Evidence from Indian Households, manuscript, Harvard University.

Paxson, Christina H. 1992. "Using Weather Variability to Estimate the Response of Savings to Transitory Income in Thailand," American Economic Review 82(1): 15-33.

Pistaferri, Luigi. 2001. "Superior Information, Income Shocks and the Permanent Income Hypothesis," Review of Economics and Statistics 83(3):465-476.

Pollak, Robert A.. 1976. "Interdependent Preferences," American Economic Review 66(3): 309-320.

Rosenzweig, Mark R.. 2001. "Savings Behaviour in Low-Income Countries," Oxford Review of Economic Policy 17(1):40-54. 
Rosenzweig, Mark R., and Kenneth I. Wolpin. 1993. "Credit Market Constraints and the Accumulation of Durable Production Assets in Low-income Countries: Investments in Bullocks," Journal of Political Economy 101(2): 223-244.

Shields, Michael A., and Stephen Wheatley Price. 2005. "Exploring the Economic and Social Determinants of Psychological Well-Being and Perceived Social Support in England," Journal of the Royal Statistical Society: Series A (Statistics in Society) 168(3): 513-537.

Souleles, Nicholas S.. 2000. "College Tuition and Household Saving and Consumption," Journal of Public Economics 77(2):185-207.

Stevenson, Betsey, and Justin Wolfers. 2008. "Economic Growth and Subjective Well-Being: Reassessing the Easterlin Paradox," Brookings Papers on Economic Activity, Economic Studies Program The Brookings Institution, vol. 39:1-102.

Stutzer, Alois. 2004. "The Role of Income Aspirations in Individual Happiness," Journal of Economic Behavior and Organization 54(1):89-109.

Veenhoven, Ruut. 1991. “Is Happiness Relative?” Social Indicators Research 24(1): 1-34.

Veenhoven, Ruut, and Floris Vergunst. 2013. "The Easterlin Illusion: Economic Gowth Does Go with Greater Happiness,” MPRA Paper 43983, University Library of Munich, Germany.

Winkelmann, Liliana, and Rainer Winkelmann. 1998. "Why Are the Unemployed So Unhappy? Evidence from Panel Data," Economica 65(257): 1-15.

Wooldridge, Jeffrey M.. 2002. "Inverse Probability Weighted M-Estimators for Sample Selection, Attrition and Stratification," Portuguese Economic Journal 1(2): 117-139. 


\section{Appendix 1}

\section{Questions on Self-reported Income in the Questionnaires}

The self-reported income questions are:

Using the scale 1-10 to represent the economic situation (income, wealth) of people in your village, 10 being the best economic conditions and 1 being the worst economic conditions,

(1) What score reflects your current economic situation?

(2) What score reflects your economic situation three years ago?

(3) What score reflects your economic situation three years from now? 


\section{Appendix 2}

We can generate a similar prediction for a general utility function if we define subjective well-being to be expected lifetime utility (current utility plus discounted future utility). Taking a Taylor expansion of $u\left(c_{t+s}\right)$ around $c_{t}$, there exists some $\tilde{c}_{s}$ lying between $c_{t+s}$ and $c_{t}$ such that

$$
u\left(c_{t+s}\right)=u\left(c_{t}\right)+u^{\prime}\left(c_{t}\right)\left(c_{t+s}-c_{t}\right)+\frac{u^{\prime \prime}\left(\tilde{c}_{s}\right)}{2}\left(c_{t+s}-c_{t}\right)^{2}
$$

By taking expectations at time $t$ of both sides of equation (A1), we get

$$
E_{t}\left[u\left(c_{t+s}\right)\right]=u\left(c_{t}\right)-\frac{b}{2} \operatorname{Var}_{t}\left(c_{t+s}\right) \cdot{ }^{20}
$$

Therefore,

$$
V_{t}=E_{t}\left[\sum_{s=0}^{\infty} \beta^{s} u\left(c_{t+s}\right)\right]=\frac{1}{1-\beta} u\left(c_{t}\right)-\frac{b}{2} \sum_{s=1}^{\infty} \beta^{s} \operatorname{Var}_{t}\left(c_{t+s}\right)
$$

Taking first differences of both sides yields:

$$
\Delta V_{t}=\frac{1}{1-\beta} \Delta u\left(c_{t}\right)
$$

From (A1) and (A2), we get the following:

$$
\Delta V_{t}=\frac{u^{\prime}\left(c_{t-1}\right)}{1-\beta} \Delta c_{t}-\frac{b}{2(1-\beta)}\left(\Delta c_{t}\right)^{2}
$$

Therefore,

$$
\Delta V_{t}=\frac{u^{\prime}\left(c_{t-1}\right)}{1-\beta}\left(\eta_{t}+\frac{r}{1+r} \delta_{t}\right)-\frac{b}{2(1-\beta)}\left(\eta_{t}+\frac{r}{1+r} \delta_{t}\right)^{2}
$$

From equation (A4), we know $\frac{\partial\left(\Delta V_{t}\right)}{\partial \eta_{t}}=\frac{u^{\prime}\left(c_{t}\right)}{1-\beta}$, and $\frac{\partial\left(\Delta V_{t}\right)}{\partial \delta_{t}}=\frac{r}{1+r} \frac{u^{\prime}\left(c_{t}\right)}{1-\beta}$. This suggests that a permanent income shock has a greater effect on well-being than a transitory income shock.

\footnotetext{
${ }^{20}$ For quadratic preferences, we have $u^{\prime \prime}\left(\tilde{c}_{s}\right)=-b$, which is constant. This helps to simplify the expectation of the third term in equation (A1). For a class of more general utility functions with property of constant relative risk aversion (CRRA), this can be approximated by some constant under certain assumption. Details are included in the Appendix 3.
} 


\section{Appendix 3}

\section{Income Process: ARMA $(p, q)$}

Our empirical specification assumes the income process is the sum of a random walk and white noise. Here, we consider another income process following Flavin (1981), and investigate its implications for the theoretical predictions about the effect of income shocks on welfare.

Suppose income follows an $\operatorname{ARMA}(p, q)$ process:

$$
x_{t}=A(L) x_{t}+[1+M(L)] \eta_{t}
$$

where $A(L)=\rho_{1} L+\rho_{2} L^{2}+\cdots \rho_{p} L^{p}, M(L)=\phi_{1} L+\phi_{2} L^{2}+\cdots \phi_{q} L^{q}, L$ is lag operator, and sequence $\left\{\eta_{t}\right\}$ is white noise. The above ARMA process can be rewritten as a moving average process:

$$
x_{t}=\frac{1+M(L)}{1-A(L)} \eta_{t}=\eta_{t}+\psi_{1} \eta_{t-1}+\psi_{2} \eta_{t-2}+\psi_{3} \eta_{t-3}+\cdots
$$

where $\psi_{s}=\phi_{s}+\sum_{j=1}^{s} \rho_{j} \psi_{s-j}$ and $\psi_{0}=1$. Therefore, $E_{t+1} x_{t+s+1}-E_{t} x_{t+s+1}=\psi_{s} \eta_{t+1}$.

Substituting into (3) gives $c_{t+1}-c_{t}=\gamma \eta_{t+1}$, where $\gamma=r \sum_{s=0}^{\infty}\left(\frac{1}{1+r}\right)^{s+1} \psi_{s}>0$.

$\operatorname{Var}_{t}\left(c_{t+s}\right)$ is independent of $t$, given that sequence $\left\{\eta_{t}\right\}$ is a white noise. Thus, equation (8) still holds. We then can derive following equation similar to (10)

$$
\Delta V_{t}=\frac{u^{\prime}\left(c_{t-1}\right)}{1-\beta}\left(\gamma \eta_{t+1}\right)-\frac{b}{2(1-\beta)}\left(\gamma \eta_{t+1}\right)^{2}
$$

Unlike equation (A4), in this equation, we can't easily tell how the effect on well-being of different income shocks is related to the persistency of the shocks. Consider two cases. In first case, $p=1$, $q=0$, and $\rho_{1}=1$, the income process becomes $x_{t}=x_{t-1}+\eta_{t}$. It's a moving average process in which income innovation in each period will affect both current and future income. In this case, $\gamma=1$. The marginal effect of the income shock on well-being is $\frac{u^{\prime}\left(c_{t}\right)}{1-\beta}$. In the second case, where $p=0$ and $q=0$, the income process is actually white noise. $\gamma=\frac{r}{1+r}$. The marginal well- effect of the income 
shock turns out to be $\frac{r}{1+r} \frac{u^{\prime}\left(c_{t}\right)}{1-\beta}$, which is smaller than the effect of the income shock in a moving average process. By comparing the above two cases, we show that the effect of an income shock is determined by the persistence of the income shock. 


\section{Appendix 4}

\section{CRRA Preferences}

In the benchmark model, we assume that preferences are quadratic. Here, we consider what happens if preferences exhibit constant relative risk aversion (CRRA), following the method used in Blundell, Low, and Preston (2004) and Blundell, Pistaferri, and Preston (2008).

\section{A.4.1 Approximating the Euler Equation}

Consider a utility function $u(c)=\frac{c^{1-\rho}}{1-\rho}, 0<\rho<1$. The Euler equation turns out to be

$$
c_{t}^{-\rho}=\beta(1+r) E_{t}\left(c_{t+1}^{-\rho}\right),
$$

Noting $c_{t+1}^{-\rho}=e^{-\rho \ln \left(c_{t+1}\right)}$ and assuming $\beta(1+r)=1$, (A5) can be rewritten as

$$
e^{-\rho \ln \left(c_{t}\right)}=E_{t}\left(e^{-\rho \ln \left(c_{t+1}\right)}\right)
$$

Take a Taylor expansion of $\mathrm{f}(\mathrm{y})=e^{-\rho \mathrm{y}}$ around $y_{0}=\ln \left(c_{t}\right)$, and evaluate it at $y=\ln \left(c_{t+1}\right)$. There exists some $\tilde{c}$ between $c_{t}$ and $c_{t+1}$ such that

$$
c_{t+1}^{-\rho}=c_{t}^{-\rho}\left[1-\rho\left(\Delta \ln \left(c_{t+1}\right)\right)+\frac{\rho^{2}}{2}\left(\frac{\tilde{c}}{c_{t}}\right)^{-\rho}\left(\Delta \ln \left(c_{t+1}\right)\right)^{2}\right]
$$

Take expectations of (A6)

$$
E_{t}\left(c_{t+1}^{-\rho}\right)=c_{t}^{-\rho}\left\{1-\rho E_{t}\left(\Delta \ln \left(c_{t+1}\right)\right)+\frac{\rho^{2}}{2} E_{t}\left[\left(\frac{\tilde{c}}{c_{t}}\right)^{-\rho}\left(\Delta \ln \left(c_{t+1}\right)\right)^{2}\right]\right\} .
$$

Substituting for $E_{t}\left(c_{t+1}^{-\rho}\right)$ from (A1),

$$
E_{t}\left(\Delta \ln \left(c_{t+1}\right)\right)=\frac{\rho}{2} E_{t}\left[\left(\frac{\tilde{c}}{c_{t}}\right)^{-\rho}\left(\Delta \ln \left(c_{t+1}\right)\right)^{2}\right] .
$$

$\zeta_{\mathrm{t}+1} \equiv \ln \left(c_{t+1}\right)-E_{t}\left(\ln \left(c_{t+1}\right)\right)$. Then,

$$
\Delta \ln \left(c_{t+1}\right)=\zeta_{t+1}+\frac{\rho}{2} E_{t}\left[\left(\frac{\tilde{c}}{c_{t}}\right)^{-\rho}\left(\Delta \ln \left(c_{t+1}\right)\right)^{2}\right] .
$$

Noting that $E_{t}\left(\zeta_{t+1}^{2}\right)=E_{t}\left[\left(\Delta \ln \left(c_{t+1}\right)\right)^{2}\right]-\left[E_{t}\left(\Delta \ln \left(c_{t+1}\right)\right)\right]^{2}$ and substituting $E_{t}\left(\Delta \ln \left(c_{t+1}\right)\right)$ from (A7), we get $E_{t}\left[\left(\Delta \ln \left(c_{t+1}\right)\right)^{2}\right]=O\left(E_{t}\left(\zeta_{t+1}^{2}\right)\right)$. As $E_{t}\left(\zeta_{t+1}^{2}\right) \rightarrow 0,\left(\frac{\tilde{c}}{c_{t}}\right)^{-\rho}$ tends to be constant. Therefore,

$$
\Delta \ln \left(c_{t+1}\right)=\zeta_{t+1}+O\left(E_{t}\left(\zeta_{t+1}^{2}\right)\right)
$$

Equation (A8) relates consumption growth to its innovations. The order of error in approximation is $\mathrm{O}\left(E_{t}\left(\zeta_{t+1}^{2}\right)\right)$.

\section{A.3.2 Approximating the Lifetime Budget Constraint}

Consider the lifetime budget constraint 


$$
\sum_{s=0}^{\infty}\left(\frac{1}{1+r}\right)^{s+1}\left(c_{t+s}\right)=w_{t}+\sum_{s=0}^{\infty}\left(\frac{1}{1+r}\right)^{s+1}\left(x_{t+s}\right) .
$$

Log-linearizing both sides, we get

$$
\begin{aligned}
& \sum_{s=0}^{\infty} \alpha_{s, t ; c}\left[\ln \left(c_{t+s}\right)-E_{t}\left(\ln \left(c_{t+s}\right)\right]+O\left(\left\|\zeta^{t}\right\|^{2}\right)\right. \\
= & \pi_{t} \sum_{s=0}^{\infty} \alpha_{s, t ; x}\left[\ln \left(x_{t+s}\right)-E_{t} \ln \left(x_{t+s}\right)\right]+O\left(\left\|v^{t}\right\|^{2},\right.
\end{aligned}
$$

where $\pi_{t}=\frac{\sum_{j=1}^{\infty} \exp \left[E_{t}\left(\ln \left(x_{t+j}\right)-(1+j) \ln (1+r)\right]\right.}{w_{t}+\sum_{j=0}^{\infty} \exp \left[E_{t}\left(\ln \left(x_{t+j}\right)-(1+j) \ln (1+r)\right]\right.}$, and $\alpha_{s, t ; q}=\frac{\exp \left[E_{t}\left(\ln \left(q_{t+s}\right)-(1+s) \ln (1+r)\right]\right.}{\sum_{j=1}^{\infty} \exp \left[E_{t}\left(\ln \left(q_{t+j}\right)-(1+j) \ln (1+r)\right]\right.}$, $q=c, x .\left\|\zeta^{t}\right\|^{2}=\sum_{s=0}^{\infty} \zeta_{t+s}^{2}$, and $\left\|v^{t}\right\|^{2}=\sum_{s=0}^{\infty}\left[\ln \left(x_{t+s}\right)-E_{t}\left(\ln \left(c_{t+s}\right)\right]^{2}\right.$. Assume that log income follows the process of the sum of a random walk and an i.i.d. component, and define $y_{t} \equiv \ln \left(x_{t}\right)$ :

$$
\begin{aligned}
& y_{t}=y_{t}^{P}+\delta_{t}, \\
& y_{t}^{P}=y_{t-1}^{P}+\varepsilon_{t} .
\end{aligned}
$$

Taking expectations of (A9) and then differences between expectations of $E_{t+1}$ and $E_{t}$ gives

$$
\begin{aligned}
\zeta_{t+1}+O\left(\zeta_{t+1}^{2}\right)+O\left(E_{t} \zeta_{t+1}^{2}\right)= & \pi_{t}\left(\varepsilon_{t+1}+\alpha_{t ; x} \delta_{t+1}\right)+O\left(\varepsilon_{t+1}^{2}\right)++O\left(E_{t} \varepsilon_{t+1}^{2}\right) \\
& +O\left(\delta_{t+1}^{2}\right)+O\left(E_{t} \delta_{t+1}^{2}\right)
\end{aligned}
$$

where $\alpha_{t ; x}=\alpha_{1, t ; x}$. Noting the terms which are $O\left(E_{t} \zeta_{t+1}^{2}\right)$ are $O\left(E_{t} \varepsilon_{t+1}^{2}\right)+O\left(E_{t} \delta_{t+1}^{2}\right)$, we then get

$$
\Delta \ln \left(c_{t+1}\right)=\pi_{t}\left(\varepsilon_{t+1}+\alpha_{t ; x} \delta_{t+1}\right)+O\left(\varepsilon_{t+1}^{2}\right)+O\left(E_{t} \varepsilon_{t+1}^{2}\right)+O\left(\delta_{t+1}^{2}\right)+O\left(E_{t} \delta_{t+1}^{2}\right) .
$$

\section{A.3.3 Approximating the Value Function}

Now we consider the theoretical prediction for the effect of income shocks on $V_{t}$. Taking a Taylor expansion of $\mathrm{g}(\mathrm{y})=\frac{1}{1-\rho} \exp [(1-\rho) y]$ around $y_{0}=\ln \left(c_{t}\right)$ and evaluating it at $\mathrm{y}=\ln \left(c_{t+s}\right)$,

$$
u\left(c_{t+s}\right)=u\left(c_{t}\right)\left[1+(1-\rho)\left(\ln \left(c_{t+s}\right)-\ln \left(c_{t}\right)\right)+\frac{(1-\rho)^{2}}{2}\left(\frac{\tilde{c}_{s, t}}{c_{t}}\right)^{1-\rho}\left(\ln \left(c_{t+s}\right)-\ln \left(c_{t}\right)\right)^{2}\right]
$$

where $\tilde{c}_{s, t}$ is between $c_{t}$ and $c_{t+s}$. Taking expectations at time $t$ on both sides, we get

$$
E_{t}\left(u\left(c_{t+s}\right)\right)=u\left(c_{t}\right)\left[1+(1-\rho) E_{t}\left(\ln \left(c_{t+s}\right)-\ln \left(c_{t}\right)\right)+\frac{(1-\rho)^{2}}{2} E_{t}\left(\left(\frac{\tilde{c}_{s, t}}{c_{t}}\right)^{1-\rho}\left(\ln \left(c_{t+s}\right)-\ln \left(c_{t}\right)\right)^{2}\right)\right]
$$

Noting that $E_{t}\left(\ln \left(c_{t+s}\right)-\ln \left(c_{t}\right)\right)$ and $E_{t}\left(\ln \left(c_{t+s}\right)-\ln \left(c_{t}\right)\right)^{2}$ are independent of $t$, substituting $E_{t}\left(u\left(c_{t+s}\right)\right)$ from the value function $V_{t}=E_{t}\left[\sum_{s=0}^{\infty} \beta^{s} u\left(c_{t+s}\right)\right]$, and taking differences, we get

$$
\begin{aligned}
\Delta V_{t+1}= & \left\{\frac{1}{1-\beta}+(1-\rho) \sum_{s=0}^{\infty} \beta^{s} E_{t}\left(\ln \left(c_{t+s}\right)-\ln \left(c_{t}\right)\right)\right. \\
& \left.+\frac{(1-\rho)^{2}}{2} \sum_{s=0}^{\infty} \beta^{s} E_{t}\left[\left(\frac{\tilde{c}_{s, t}}{c_{t}}\right)^{1-\rho}\left(\ln \left(c_{t+s}\right)-\ln \left(c_{t}\right)\right)^{2}\right]\right\} \Delta u\left(c_{t+1}\right) .
\end{aligned}
$$

From (A11) we can derive the expression for $\Delta u\left(c_{t+1}\right)$. Substituting from (A12), we get 


$$
\begin{aligned}
\Delta V_{t+1}= & \frac{(1-\rho) u\left(c_{t}\right)}{1-\beta} \Delta \ln \left(c_{t+1}\right)+(1-\rho) u\left(c_{t}\right) \Delta \ln \left(c_{t+1}\right) O\left(\left\|\zeta^{t}\right\|^{2}\right) \\
& +O\left[\left(\Delta \ln \left(c_{t+1}\right)\right)^{2}\right]+O\left(\left\|\zeta^{t}\right\|^{2}\right) O\left[\left(\Delta \ln \left(c_{t+1}\right)\right)^{2}\right]
\end{aligned}
$$

Substitute $\Delta \ln \left(c_{t+1}\right)$ from (A10),

$$
\Delta V_{t+1}=\frac{(1-\rho) u\left(c_{t}\right)}{1-\beta} \pi_{t}\left(\varepsilon_{t+1}+\alpha_{t ; x} \delta_{t+1}\right)+O\left(\varepsilon_{t+1}^{2}\right)+O\left(E_{t} \varepsilon_{t+1}^{2}\right)+O\left(\delta_{t+1}^{2}\right)+O\left(E_{t} \delta_{t+1}^{2}\right)
$$

This equation links change in welfare and income innovations. Since $\alpha_{t ; x}<1$, ignoring the error in the approximation, the model with CRRA preference has the same prediction as that assuming a quadratic utility function. That is, the impact of permanent income shocks on welfare is greater than that of transitory income shocks. 


\section{Appendix 5}

\section{Welfare Implication of Negative Transitory Income Shocks}

\section{when the Credit Market is Imperfect}

Taking Taylor expansion of $u\left(c_{t+s}\right)$ around $c_{t}^{*}$,

$$
u\left(c_{t+s}\right)=u\left(c_{t}^{*}\right)+u^{\prime}\left(c_{t}^{*}\right)\left(c_{t+s}-c_{t}^{*}\right)+\frac{u^{\prime \prime}\left(\tilde{c}_{s}\right)}{2}\left(c_{t+s}-c_{t}^{*}\right)^{2}
$$

where $c_{t}^{*}$ is the optimal consumption choice in benchmark model and $\tilde{c}_{s}$ lies between $c_{t+s}$ and $c_{t}^{*}$.

Case 1: $E_{t-1} c_{t+1}=0$

For $s=0, u\left(c_{t}\right)=u\left(c_{t}^{*}\right)-u^{\prime}\left(c_{t}^{*}\right)\left(\frac{\left|\delta_{t}\right|}{1+r}\right)+\frac{u^{\prime \prime}\left(\tilde{c}_{s}\right)}{2}\left(\frac{\left|\delta_{t}\right|}{1+r}\right)^{2}$.

For $s>0$,

$$
E_{t}\left[u\left(c_{t+s}\right)\right]=u\left(c_{t}^{*}\right)+u^{\prime}\left(c_{t}^{*}\right)\left(\frac{r\left|\delta_{t}\right|}{1+r}\right)+\frac{u^{\prime \prime}\left(\tilde{c}_{s}\right)}{2} E_{t}\left(c_{t+s}-E_{t} c_{t+s}+\frac{r\left|\delta_{t}\right|}{1+r}\right)^{2} .
$$

Therefore, $V_{t}=\frac{1}{1-\beta} u\left(c_{t}^{*}\right)-\frac{b}{2}\left(\frac{\left|\delta_{t}\right|}{1+r}\right)^{2}-\frac{b}{2} \frac{\beta}{1-\beta}\left(\frac{r\left|\delta_{t}\right|}{1+r}\right)^{2}-\frac{b}{2} \sum_{s=1}^{\infty} \beta^{s} \operatorname{Var}_{t}\left(c_{t+s}\right)$.

$$
V_{t}^{*}-V_{t}=\frac{b}{2}\left(\frac{\left|\delta_{t}\right|}{1+r}\right)^{2}+\frac{b}{2} \frac{\beta}{1-\beta}\left(\frac{r\left|\delta_{t}\right|}{1+r}\right)^{2}=\frac{b}{2} \beta \delta_{t}^{2}
$$

where $V_{t}^{*}$ the welfare achieved in the benchmark model.

Case 2: $0<E_{t-1}\left(w_{t+1}\right)<\left|\delta_{t}\right| /(1+r)$ or partially self-finance

Define $w=E_{t-1}\left(w_{t+1}\right)$

For $s=0, u\left(c_{t}\right)=u\left(c_{t}^{*}\right)-u^{\prime}\left(c_{t}^{*}\right)\left(\frac{\left|\delta_{t}\right|}{1+r}-w\right)+\frac{u^{\prime \prime}\left(\tilde{c}_{s}\right)}{2}\left(\frac{\left|\delta_{t}\right|}{1+r}-w\right)^{2}$.

For $s>0$,

$$
E_{t}\left[u\left(c_{t+s}\right)\right]=u\left(c_{t}^{*}\right)+u^{\prime}\left(c_{t}^{*}\right)\left(\frac{r\left|\delta_{t}\right|}{1+r}-r w\right)+\frac{u^{\prime \prime}\left(\tilde{c}_{s}\right)}{2} E_{t}\left(c_{t+s}-E_{t} c_{t+s}+\frac{r\left|\delta_{t}\right|}{1+r}-r w\right)^{2} .
$$


Therefore, $V_{t}=\frac{1}{1-\beta} u\left(c_{t}^{*}\right)-\frac{b}{2}\left(\frac{\left|\delta_{t}\right|}{1+r}-w\right)^{2}-\frac{b}{2} \frac{\beta}{1-\beta}\left(\frac{r\left|\delta_{t}\right|}{1+r}-r w\right)^{2}-\frac{b}{2} \sum_{s=1}^{\infty} \beta^{s} \operatorname{Var}_{t}\left(c_{t+s}\right)$

$$
V_{t}^{*}-V_{t}=\frac{b}{2}\left(\frac{\left|\delta_{t}\right|}{1+r}-w\right)^{2}+\frac{b}{2} \frac{\beta}{1-\beta}\left(\frac{r\left|\delta_{t}\right|}{1+r}-r w\right)^{2}=b\left(\beta\left|\delta_{t}\right|-w\right)^{2} / 2 \beta
$$

where $V_{t}^{*}$ the welfare achieved in the benchmark model. 


\section{Appendix 6}

Consider a regression model $y=\alpha_{0}+\alpha\left(x_{1}+x_{2}\right)+e$, the OLS estimator of $\alpha$ is

$$
\hat{\alpha}=\frac{\operatorname{cov}\left(y, x_{1}+x_{2}\right)}{\operatorname{var}\left(x_{1}+x_{2}\right)} \text {. }
$$

For the other regression model $y=\alpha_{0}^{\prime}+\alpha_{1} x_{1}+\alpha_{2} x_{2}+e^{\prime}$, the OLS estimators are

$$
\begin{aligned}
& \hat{\alpha}_{1}=\frac{\operatorname{var}\left(x_{2}\right) \operatorname{cov}\left(y, x_{1}\right)-\operatorname{cov}\left(x_{1}, x_{2}\right) \operatorname{cov}\left(y, x_{2}\right)}{\operatorname{var}\left(x_{1}\right)+\operatorname{var}\left(x_{2}\right)-\operatorname{cov}\left(x_{1}, x_{2}\right)^{2}}, \text { and } \\
& \hat{\alpha}_{2}=\frac{\operatorname{var}\left(x_{1}\right) \operatorname{cov}\left(y, x_{2}\right)-\operatorname{cov}\left(x_{1}, x_{2}\right) \operatorname{cov}\left(y, x_{1}\right)}{\operatorname{var}\left(x_{1}\right)+\operatorname{var}\left(x_{2}\right)-\operatorname{cov}\left(x_{1}, x_{2}\right)^{2}} .
\end{aligned}
$$

It can be shown that

$$
\hat{\alpha}=w \hat{\alpha}_{1}+(1-w) \hat{\alpha}_{2},
$$

where $w=\frac{\operatorname{var}\left(x_{1}\right)+\operatorname{cov}\left(x_{1}, x_{2}\right)}{\operatorname{var}\left(x_{1}+x_{2}\right)} .0<w<1$, if and only if $\operatorname{var}\left(x_{1}\right)+\operatorname{cov}\left(x_{1}, x_{2}\right)>0$ and $\operatorname{var}\left(x_{2}\right)+\operatorname{cov}\left(x_{1}, x_{2}\right)>0$.

In a more general case, the two regression models are

$$
\begin{aligned}
& y=\beta_{0}+\beta\left(x_{1}+x_{2}\right)+\gamma Z+u, \\
& y=\beta_{0}^{\prime}+\beta_{1} x_{1}+\beta_{2} x_{2}+\gamma^{\prime} Z+u^{\prime},
\end{aligned}
$$

where $Z$ are a vector of other regressors. We have $\hat{\beta}=\bar{w} \hat{\beta}_{1}+(1-\bar{w}) \hat{\beta}_{2}$, where $\bar{w}=w+$ $\frac{\left(\widehat{\gamma}^{\prime}-\widehat{\gamma}\right) \cdot \widehat{\theta}}{\widehat{\beta}_{1}-\widehat{\beta}_{2}} . \hat{\beta}_{1}, \hat{\beta}_{2}, \hat{\gamma}, \hat{\gamma}^{\prime}$ are OLS estimators of above regression models. $\hat{\theta}$ are the estimators of the regression model $Z=\theta_{0}+\theta\left(x_{1}+x_{2}\right)+\epsilon$. Under the assumption that $\frac{\left(\widehat{\gamma}^{\prime}-\widehat{\gamma}\right) \cdot \widehat{\theta}}{\widehat{\beta}_{1}-\widehat{\beta}_{2}}=0$, we have $\bar{w}=w=\frac{\operatorname{var}\left(x_{1}\right)+\operatorname{cov}\left(x_{1}, x_{2}\right)}{\operatorname{var}\left(x_{1}+x_{2}\right)}$. By further assuming $\operatorname{cov}\left(x_{1}, x_{2}\right)=0$, we have $\bar{w}=$ $\frac{\operatorname{var}\left(x_{1}\right)}{\operatorname{var}\left(x_{1}\right)+\operatorname{var}\left(x_{2}\right)}$ 
Table 1: Descriptive Statistics

\begin{tabular}{|c|c|c|c|c|}
\hline \multirow{2}{*}{ Variables } & \multicolumn{2}{|c|}{ Year 2006} & \multicolumn{2}{|c|}{ Year 2009} \\
\hline & Mean & S. D. & Mean & S. D. \\
\hline Global life satisfaction (1-5) & 3.81 & 0.86 & 3.74 & 0.76 \\
\hline Income (rank in village: $1-10)$ & 5.37 & 2.70 & 5.02 & 2.70 \\
\hline Expectation of income three years later (rank in village: $1-10$ ) & 6.02 & 2.21 & 6.04 & 1.83 \\
\hline Age & 36.7 & 13.7 & 39.7 & 13.7 \\
\hline Male (dummy) & 0.59 & 0.49 & 0.59 & 0.49 \\
\hline Married (dummy) & 0.71 & 0.45 & 0.73 & 0.44 \\
\hline Less than primary school education (dummy) & 0.20 & 0.40 & 0.19 & 0.39 \\
\hline Primary school education (dummy) & 0.25 & 0.44 & 0.28 & 0.45 \\
\hline Middle school education (dummy) & 0.28 & 0.45 & 0.26 & 0.44 \\
\hline High/vocational school education (dummy) & 0.24 & 0.43 & 0.17 & 0.37 \\
\hline College or above education (dummy) & 0.03 & 0.17 & 0.11 & 0.31 \\
\hline Household size & 3.92 & 1.38 & 3.95 & 1.57 \\
\hline Number of migrants in household & 0.83 & 0.99 & 0.59 & 0.82 \\
\hline Share of family member aged $<18$ & 0.19 & 0.17 & 0.12 & 0.17 \\
\hline Share of family member aged $>60$ & 0.05 & 0.10 & 0.08 & 0.15 \\
\hline Log of income per capita & 8.20 & 0.90 & 8.46 & 0.81 \\
\hline
\end{tabular}

Notes: The sample size is 960 for each year. Means and standard deviations are estimated using inverse probability weights to adjust for sample selection and attrition. 
Table 2: Income and Well-being: Comparison between Cross-sectional and Panel Analysis

\begin{tabular}{|c|c|c|c|c|c|c|c|c|}
\hline & \multicolumn{8}{|c|}{ Dependent variable: global life satisfaction } \\
\hline & \multicolumn{2}{|c|}{$(1)$} & \multicolumn{2}{|c|}{$(2)$} & \multicolumn{2}{|c|}{$(3)$} & \multicolumn{2}{|c|}{$(4)$} \\
\hline & coef. & s.e. & coef. & s.e. & coef. & s.e. & coef. & s.e. \\
\hline Individual fixed effect? & \multicolumn{2}{|c|}{$\mathrm{N}$} & \multicolumn{2}{|c|}{$\mathrm{Y}$} & \multicolumn{2}{|c|}{$\mathrm{N}$} & \multicolumn{2}{|c|}{$\mathrm{Y}$} \\
\hline Log household income p.c. & $0.154 * * *$ & $(0.037)$ & 0.074 & $(0.054)$ & $0.154 * * *$ & $(0.043)$ & $0.089 *$ & $(0.052)$ \\
\hline Mean of log household income p.c. in village & & & & & -0.000 & $(0.075)$ & -0.142 & $(0.163)$ \\
\hline Age & $-0.056^{*}$ & $(0.031)$ & n.a. & n.a. & $-0.056^{*}$ & $(0.031)$ & n.a. & n.a. \\
\hline$(\mathrm{Age} / 10)^{\wedge} 2$ & $0.081 * *$ & $(0.036)$ & $0.183^{* *}$ & $(0.089)$ & $0.081 * *$ & $(0.036)$ & $0.174^{*}$ & $(0.092)$ \\
\hline Male (dummy) & $-0.135^{*}$ & $(0.072)$ & n.a. & n.a. & $-0.135^{*}$ & $(0.072)$ & n.a. & n.a. \\
\hline Married (dummy) & 0.019 & $(0.168)$ & -0.251 & $(0.264)$ & 0.019 & $(0.167)$ & -0.248 & $(0.262)$ \\
\hline Education=primary school & -0.000 & $(0.073)$ & 0.037 & $(0.122)$ & -0.000 & $(0.072)$ & 0.043 & $(0.123)$ \\
\hline Education=middle school & $0.138^{*}$ & $(0.076)$ & $0.267 *$ & $(0.157)$ & $0.138^{*}$ & $(0.076)$ & $0.273^{*}$ & $(0.157)$ \\
\hline Education=high/vocational school & $0.341 * *$ & $(0.136)$ & 0.084 & $(0.255)$ & $0.341 * *$ & $(0.140)$ & 0.074 & $(0.254)$ \\
\hline Education=college or above & 0.348 & $(0.291)$ & -0.135 & $(0.377)$ & 0.348 & $(0.290)$ & -0.113 & $(0.383)$ \\
\hline Household size & 0.030 & $(0.030)$ & -0.007 & $(0.049)$ & 0.030 & $(0.030)$ & -0.006 & $(0.051)$ \\
\hline Number of migrants in household & 0.011 & $(0.038)$ & -0.016 & $(0.046)$ & 0.011 & $(0.037)$ & -0.015 & $(0.046)$ \\
\hline Share of family member aged $<18$ & -0.106 & $(0.210)$ & -0.417 & $(0.390)$ & -0.106 & $(0.206)$ & -0.473 & $(0.381)$ \\
\hline Share of family member aged $>60$ & $-0.416^{*}$ & $(0.231)$ & 0.434 & $(0.462)$ & $-0.416^{*}$ & $(0.234)$ & 0.461 & $(0.468)$ \\
\hline Year 2009 (dummy) & -0.116 & $(0.072)$ & $-0.531 * *$ & $(0.267)$ & -0.116 & $(0.081)$ & -0.448 & $(0.304)$ \\
\hline Constant & $3.210 * * *$ & $(0.808)$ & 0.569 & $(1.475)$ & $3.211 * * *$ & $(0.955)$ & 1.789 & $(2.286)$ \\
\hline Observations & 1,920 & & 1,920 & & 1,920 & & 1,920 & \\
\hline R-squared & 0.071 & & 0.059 & & 0.071 & & 0.061 & \\
\hline Number of individuals & & & 960 & & & & 960 & \\
\hline
\end{tabular}

Notes: All regressions are adjusted with IPW. Omitted category for education is the group of less than primary school education. Standard errors in brackets are clustered in

households. ${ }^{* * *} \mathrm{p}<0.01,{ }^{* *} \mathrm{p}<0.05,{ }^{*} \mathrm{p}<0.1$ 
Table 3: Expected and Unexpected Income

\begin{tabular}{lccc}
\hline \hline & \multicolumn{3}{c}{ Dependent variable: global life satisfaction } \\
\cline { 2 - 4 } & $(1)$ & $(2)$ & $(3)$ \\
\hline & & & $0.028^{* *}$ \\
Unexpected income shock $\left(\tilde{\beta_{2}}\right)$ & $0.016^{*}$ & & {$[0.013]$} \\
& {$[0.009]$} & & 0.021 \\
Expected income $\left(\tilde{\beta_{3}}\right)$ & & -0.003 & {$[0.016]$} \\
& & {$[0.011]$} & $0.163^{* * *}$ \\
Lagged global life satisfaction & $0.166^{* * *}$ & $0.164^{* * *}$ & {$[0.039]$} \\
& {$[0.039]$} & {$[0.039]$} & $\mathrm{Y}$ \\
Village fixed effect? & $\mathrm{Y}$ & $\mathrm{Y}$ & 960 \\
Observations & 960 & 960 & 0.372 \\
R-squared & 0.370 & 0.367 &
\end{tabular}

Notes:

1) Expected income is the expectation of income position in village at year 2009 which is asked in year 2006. Unexpected income shock is measured as difference between realization of income position and expected income position in village of year 2009, where the realization of income position is measured as the rank of household income per capita in the village. The expected income position has been adjusted for outlook bias. See the text for detailed information of the adjustment.

2) The sample used for all regressions are of year 2009. All regressions includes current and baseline values of the variables in Table 2, as well as variables indicating household wealth, including log of house value per capita, $\log$ of monetary value of livestock per capita, and dummies for ownership of a couple of durables (large furnisher, bicy cler, motorbike, electric battery vehicle, radio/recorder, black and white TV, color TV, telephone, mobile phone, audiovisual products, refrigerator, air conditioning, gas stove, sewing machine, camera, washing machine, electric/solar water heater, computer, dispenser, microwave, agricultural motor vehicle, and car/truck). All regressions are adjusted with IPW.

3) Standard errors in brackets are clustered in households. $* * * p<0.01,{ }^{* *} \mathrm{p}<0.05, * \mathrm{p}<0.1$. 
Table 4: Permanent and Transitory Income Shocks and SWB

\begin{tabular}{lccc}
\hline \hline & \multicolumn{3}{c}{ Dependent variable: global life satisfaction } \\
\cline { 2 - 4 } & $(1)$ & $(2)$ & $(3)$ \\
\hline & & & \\
Permanent income shock $\left(\beta^{\prime}{ }^{4}\right)$ & $0.030^{* *}$ & & $0.039^{* * *}$ \\
& {$[0.013]$} & & {$[0.014]$} \\
Transitory income shock $\left(\beta^{\prime}{ }^{5}\right)$ & & 0.002 & 0.013 \\
& & {$[0.009]$} & {$[0.009]$} \\
Lagged global life satisfaction & $0.169^{* * *}$ & $0.163^{* * *}$ & $0.170^{* * *}$ \\
& {$[0.039]$} & {$[0.039]$} & {$[0.039]$} \\
Village fixed effect? & $\mathrm{Y}$ & $\mathrm{Y}$ & $\mathrm{Y}$ \\
p value of Wald test on $\beta^{\prime}{ }_{4}<=\beta^{\prime}{ }_{5}$ & & & 0.0295 \\
Observations & 960 & 960 & 960 \\
R-squared & 0.372 & 0.367 & 0.374 \\
\hline
\end{tabular}

Notes:

1) Permanent income shock is measured as the difference between expectation of future income positions in the village reported in years 2006 and 2009. Transitory income shock is defined as the rest of unexpected income shocks subtracted permanent income shocks.

2) The sample used for all regressions are of year 2009. All regressions includes the same controls as in Table 3, and are adjusted with IPW.

3) Standard errors in brackets are clustered in households. ${ }^{* * *} \mathrm{p}<0.01,{ }^{* *} \mathrm{p}<0.05,{ }^{*} \mathrm{p}<0.1$. 
Table 5: Credit Accessibility and Heterogeneous Effect of Income Shocks

\begin{tabular}{|c|c|c|}
\hline & \multicolumn{2}{|c|}{ Dependent variable: global life satisfaction } \\
\hline & $(1)$ & $(2)$ \\
\hline \multirow[t]{2}{*}{ Permanent income shock ( $\left.\beta_{4}^{\prime}\right)$} & $0.038 * * *$ & $0.062 * * *$ \\
\hline & {$[0.014]$} & {$[0.020]$} \\
\hline \multirow[t]{2}{*}{ High as set $\times$ Permanent income shock } & & -0.025 \\
\hline & & {$[0.040]$} \\
\hline \multirow[t]{2}{*}{ Transitory income shock_neg ( $\left.\beta^{\prime} 5 \_n e g\right)$} & $0.026^{*}$ & $0.045^{* *}$ \\
\hline & {$[0.013]$} & {$[0.021]$} \\
\hline \multirow[t]{2}{*}{ High asset×Transitory income shock_neg } & & $-0.055^{*}$ \\
\hline & & {$[0.029]$} \\
\hline \multirow[t]{2}{*}{ Transitory income shock_pos ( $\beta^{\prime}{ }_{5} \_$pos $)$} & -0.010 & 0.001 \\
\hline & {$[0.020]$} & {$[0.028]$} \\
\hline \multirow[t]{2}{*}{ High asset×Transitory income shock_pos } & & -0.039 \\
\hline & & {$[0.028]$} \\
\hline \multirow[t]{2}{*}{ High as set } & & -0.020 \\
\hline & & {$[0.127]$} \\
\hline \multirow[t]{2}{*}{ Lagged global life satisfaction } & $0.171 * * *$ & $0.165 * * *$ \\
\hline & {$[0.039]$} & {$[0.039]$} \\
\hline Village fixed effect? & $\mathrm{Y}$ & $\mathrm{Y}$ \\
\hline $\mathrm{p}$ value of Wald test on $\beta_{4}^{\prime}<=\beta^{\prime}{ }_{5}$ neg & 0.2309 & \\
\hline $\mathrm{p}$ value of Wald test on $\beta_{4}^{\prime}<=\beta^{\prime}{ }_{5}$ pos & 0.0144 & \\
\hline Observations & 960 & 960 \\
\hline R-squared & 0.375 & 0.380 \\
\hline
\end{tabular}

Notes:

1) High asset is a dummy indicating high asset index, which is constructed by principal-component factor of log of house value per capita, log of value of livestock per capita, and dummies of a couple of durables (large furnisher, bicycler, motorbike, electric battery vehicle, radio/recorder, black and white $\mathrm{TV}$, color TV, telephone, mobile phone, audiovisual products, refrigerator, air conditioning, gas stove, sewing machine, camera, washing machine, electric/solar water heater, computer, dispenser, microwave, agricultural motor vehicle, and car/truck).

2) The sample used for all regressions are of year 2009. All regressions includes the same controls as in Table 3, and are adjusted with IPW.

3) Standard errors in brackets are clustered in households. $* * * p<0.01, * * p<0.05,{ }^{*} p<0.1$. 
Table 6: Life Span and Heterogeneous Effect of Income shocks

\begin{tabular}{|c|c|c|}
\hline & \multicolumn{2}{|c|}{ Dependent variable: global life satisfaction } \\
\hline & Young (21-45) & Old $(46-60)$ \\
\hline & $(1)$ & $(2)$ \\
\hline \multirow[t]{2}{*}{ Permanent income shock $\left(\beta^{\prime} 4\right)$} & 0.038 & $0.055^{* * *}$ \\
\hline & {$[0.024]$} & {$[0.019]$} \\
\hline \multirow[t]{2}{*}{ Transitory income shock $\left(\beta_{5}^{\prime}\right)$} & 0.004 & $0.029 * *$ \\
\hline & {$[0.018]$} & {$[0.012]$} \\
\hline \multirow[t]{2}{*}{ Lagged global life satisfaction } & $0.232 * * *$ & $0.155^{* * *} *$ \\
\hline & {$[0.060]$} & {$[0.054]$} \\
\hline Village fixed effect? & Y & $\mathrm{Y}$ \\
\hline $\mathrm{p}$ value of Wald test on $\beta^{\prime}{ }_{4}<=\beta^{\prime}{ }_{5}$ & 0.0452 & 0.0943 \\
\hline Observations & 401 & 559 \\
\hline R-squared & 0.610 & 0.375 \\
\hline \multicolumn{3}{|l|}{ Notes: } \\
\hline \multicolumn{3}{|c|}{$\begin{array}{l}\text { 1) The sample used for all regressions are of year 2009. All regressions includes the same controls as in } \\
\text { Table } 3 \text {, and are adjusted with IPW. }\end{array}$} \\
\hline
\end{tabular}

Table 7: Calibration of the Parameters from the Data

\begin{tabular}{|c|c|c|c|}
\hline \\
\hline \multicolumn{4}{|c|}{$\begin{array}{c}\text { Panel A: Variance-Covariance Matrix } \\
\qquad x_{t} \\
x_{t}{ }^{p}\end{array}$} \\
\hline \multicolumn{4}{|c|}{$\begin{array}{cccc} & x_{t} & x_{t} & o_{t} \\
x_{t} & 7.6424 & & \end{array}$} \\
\hline \multicolumn{4}{|c|}{$\begin{array}{ll}x_{t}{ }^{p} & 2.6497\end{array}$} \\
\hline \multirow[t]{2}{*}{$\delta_{t}$} & 4.9927 & -8.6732 & 13.6659 \\
\hline & $\Delta x_{t}$ & $\eta_{t}$ & $\Delta \delta_{t}$ \\
\hline \multirow{3}{*}{$\begin{array}{l}\Delta x_{t} \\
\eta_{t} \\
\Delta \delta_{t}\end{array}$} & 10.8854 & & \\
\hline & 1.1621 & 5.8256 & \\
\hline & 9.7233 & -4.6634 & 14.3868 \\
\hline
\end{tabular}

Panel B: Calibration of the weights

(1) (2)

\begin{tabular}{ccc} 
& unadjusted & adjusted \\
$\mathrm{w}_{\mathrm{c}}$ & 0.3467 & 0.3077 \\
& & \\
$\mathrm{w}_{\mathrm{p}}$ & 0.1068 & 0.0870 \\
\hline
\end{tabular}


Table 8: Explain Differences in Cross-sectional and Panel Regressions

\begin{tabular}{|c|c|c|c|c|}
\hline & \multicolumn{2}{|c|}{ SWB } & \multicolumn{2}{|c|}{ Change in SWB } \\
\hline & $(1)$ & (2) & (3) & (4) \\
\hline Income (rank in village) $(\phi)$ & $\begin{array}{c}0.034 * * * \\
{[0.012]}\end{array}$ & & & \\
\hline Lifetime income $\left(\phi_{1}\right)$ & & $\begin{array}{c}0.043 * * * \\
{[0.014]}\end{array}$ & & \\
\hline Transitory income shock $\left(\phi_{2}\right)$ & & $\begin{array}{c}0.030 * * \\
{[0.012]}\end{array}$ & & \\
\hline Change in income (rank in village) $\left(\phi^{\prime}\right)$ & & & $\begin{array}{c}0.021 * * \\
{[0.010]}\end{array}$ & \\
\hline Permanent income shock $\left(\phi 1^{\prime}\right)$ & & & & $\begin{array}{c}0.042 * * * \\
{[0.015]}\end{array}$ \\
\hline Change in transitory income shocks $\left(\phi_{2}{ }^{\prime}\right)$ & & & & $\begin{array}{c}0.019 * * \\
{[0.010]}\end{array}$ \\
\hline Village fixed effect? & Y & Y & Y & Y \\
\hline Comparing coefficients between (2) and (4) & & & & \\
\hline$p$ value of Wald test on $\phi_{1}=\phi_{1}^{\prime}$ & $\mathrm{F}(1$, & $779)=0$ & $\mathrm{~b}>\mathrm{F}=$ & 280 \\
\hline $\mathrm{p}$ value of Wald test on $\phi_{2}=\phi_{2}{ }^{\prime}$ & $\mathrm{F}(1$, & 779) $=$ & $\mathrm{b}>\mathrm{F}=$ & 796 \\
\hline Comparing coefficients within equations & & & & \\
\hline $\mathrm{p}$ value of Wald test on $\phi_{1}<=\phi_{2}$, or $\phi_{1}{ }^{\prime}<=\phi_{2}{ }^{\prime}$ & & 0.1084 & & 0.0541 \\
\hline Observations & 960 & 960 & 960 & 960 \\
\hline R-squared & 0.295 & 0.296 & 0.291 & 0.294 \\
\hline
\end{tabular}

Notes:

1) Income is defined as realization of income position in village of year 2009. Transitory and permanent income shock have the same definition as in Table 4. Lifetime income is defined as the difference between income (rank in village) and transitory income shock. Change in transitory income shocks is defined as the difference between change in income and permanent income shock.

2) All regressions control for current and baseline variables as following: age, age square, male, married, education (five categories), household size, number of migrants in the household, share of household members aged younger than 18 , share of household members aged older than 60 , as well as the lagged dependent variable. All regressions are adjusted with IPW.

3) Standard errors in brackets are clustered in households. *** $\mathrm{p}<0.01, * * \mathrm{p}<0.05$, ${ }^{*} \mathrm{p}<0.1$. 